\title{
Local-scale urban meteorological parameterization scheme (LUMPS): longwave radiation parameterization and seasonality-related developments
}

Article

Published Version

Loridan, T., Grimmond, C.S.B., Offerle, B. D., Young, D. T., Smith, T. E. L., Järvi, L. and Lindberg, F. (2011) Local-scale urban meteorological parameterization scheme (LUMPS): longwave radiation parameterization and seasonality-related developments. Journal of Applied Meteorology and Climatology, 50 (1). pp. 185-202. ISSN 1558-8424 doi: https://doi.org/10.1175/2010JAMC2474.1 Available at https://centaur.reading.ac.uk/34757/

It is advisable to refer to the publisher's version if you intend to cite from the work. See Guidance on citing.

Published version at: http://dx.doi.org/10.1175/2010JAMC2474.1

To link to this article DOI: http://dx.doi.org/10.1175/2010JAMC2474.1

Publisher: American Meteoroloigcal Society

All outputs in CentAUR are protected by Intellectual Property Rights law, including copyright law. Copyright and IPR is retained by the creators or other copyright holders. Terms and conditions for use of this material are defined in the End User Agreement. 


\section{www.reading.ac.uk/centaur}

\section{CentAUR}

Central Archive at the University of Reading

Reading's research outputs online 


\title{
Local-Scale Urban Meteorological Parameterization Scheme (LUMPS): Longwave Radiation Parameterization and Seasonality-Related Developments
}

\author{
THOMAS LORIDAN AND C. S. B. GRIMMOND \\ Department of Geography, King's College London, London, United Kingdom \\ BRIAN D. OFFERLE \\ FluxSense, Göteborg, Sweden \\ Duick T. Young And Thomas E. L. Smith \\ Department of Geography, King's College London, London, United Kingdom \\ LEENA JÄRVI \\ Department of Geography, King's College London, London, United Kingdom, and Department of Physics, \\ University of Helsinki, Helsinki, Finland \\ FREDRIK LINDBERG* \\ Department of Geography, King's College London, London, United Kingdom
}

(Manuscript received 14 January 2010, in final form 21 August 2010)

\begin{abstract}
Recent developments to the Local-scale Urban Meteorological Parameterization Scheme (LUMPS), a simple model able to simulate the urban energy balance, are presented. The major development is the coupling of LUMPS to the Net All-Wave Radiation Parameterization (NARP). Other enhancements include that the model now accounts for the changing availability of water at the surface, seasonal variations of active vegetation, and the anthropogenic heat flux, while maintaining the need for only commonly available meteorological observations and basic surface characteristics. The incoming component of the longwave radiation $(L \downarrow)$ in NARP is improved through a simple relation derived using cloud cover observations from a ceilometer collected in central London, England. The new $L \downarrow$ formulation is evaluated with two independent multiyear datasets (Łódź, Poland, and Baltimore, Maryland) and compared with alternatives that include the original NARP and a simpler one using the National Climatic Data Center cloud observation database as input. The performance for the surface energy balance fluxes is assessed using a 2-yr dataset (Łódź). Results have an overall RMSE $<34 \mathrm{~W} \mathrm{~m}^{-2}$ for all surface energy balance fluxes over the 2-yr period when using $L \downarrow$ as forcing, and RMSE $<43 \mathrm{~W} \mathrm{~m}^{-2}$ for all seasons in 2002 with all other options implemented to model $L \downarrow$.
\end{abstract}

\section{Introduction}

The characterization of surface-atmosphere energy exchange is at the core of most meteorological

\footnotetext{
* Current affiliation: Dept. of Earth Sciences, Gothenburg University, Göteborg, Sweden.

Corresponding author address: Thomas Loridan, Environmental Monitoring and Modelling Group, Dept. of Geography, King's College London, London WC2R 2LS, United Kingdom.

E-mail: thomas.loridan@gmail.com
}

applications, ranging from weather forecasting to pollutant dispersion and boundary layer height modeling. As shown by Grimmond et al. (2010a,b) in their model comparison project, no optimum compromise can yet be identified between the complexity of the parameterization schemes involved (both in terms of computational cost and amount of required input information) and their performance in simulating the main components of the surface energy balance in urban areas (SEB; Oke 1987). The Local-scale Urban Meteorological Parameterization Scheme (LUMPS) of Grimmond and Oke (2002) is by design one of the simplest models available. 
The parameterization of storage heat $\left(\Delta Q_{S}\right)$ belongs to the category of empirical models as defined by Masson (2006), as it uses observed relations between net allwave radiation $\left(Q^{*}\right)$ and surface components, which are combined based on their fractions present [Objective Hysteresis Model (OHM), Grimmond et al. (1991); Grimmond and Oke (1999)]. The turbulent fluxes of sensible heat $\left(Q_{H}\right)$ and latent heat $\left(Q_{E}\right)$ are subsequently partitioned from the available energy $\left(Q^{*}-\Delta Q_{S}\right)$ using a version of the Holtslag and van Ulden (1983) combinationtype model with coefficients determined for urban areas (Grimmond and Oke 2002). This type of approach toward modeling $Q_{H}$ is commonly used to characterize the state of the planetary boundary layer (friction velocity, mixing height, Obukhov length) in many of the meteorological preprocessors developed by the dispersion modeling community [e.g., Complex Terrain Dispersion Model (CTDM) plus algorithms for unstable situations (CTDMPLUS; Perry 1992), or Atmospheric Dispersion Modeling System (AERMOD) Meteorological Preprocessor (AERMET; Cimorelli et al. 2005)].

The original urban SEB directly modeled by LUMPS is

$$
Q^{*}=Q_{H}+Q_{E}+\Delta Q_{S}
$$

The anthropogenic heat flux $\left(Q_{F}\right)$ was initially considered to be implicitly contained within the coefficients because observations were used to derive their estimates (Grimmond and Oke 2002). However, it was stressed that the sites used in the derivation did not include large $Q_{F}$ fluxes relative to the radiative forcing, so consequently they were not explicitly included (Grimmond and Oke 2002). Microscale advection processes are included within the parameterization implicitly. The net advection of heat and moisture $\left(\Delta Q_{A}\right)$ from larger-scale patchiness (such as between neighborhoods) is not included in the model, as with other urban land surface schemes (Grimmond et al. 2010a,b) a mesoscale model is needed to resolve this (in which LUMPS would be embedded if "online"). The original LUMPS is able to simulate the SEBs of urban areas if provided with observations of $Q^{*}$ and common meteorological variables (air temperature, pressure, humidity, and precipitation) at the local or neighborhood scales $\left(10^{2}-10^{4} \mathrm{~m}\right)$ along with basic surface cover information (fraction of surface area occupied by vegetation, buildings, or impervious materials).

The most restrictive of these requirements is the need for $Q^{*}$ at the local scale. To eliminate this dependency, the Net All-wave Radiation Parameterization (NARP) of Offerle et al. (2003) is incorporated. Instead of $Q^{*}$, incoming shortwave radiation $(K \downarrow)$, near-surface air temperature $\left(T_{a}\right)$, vapor pressure $\left(e_{a}\right)$, and relative humidity
(RH) are required, along with bulk surface albedo and emissivity estimates ( $\alpha_{0}$ and $\varepsilon_{0}$, respectively). The combined LUMPS-NARP system (hereafter referred to as LUMPS) is easily employed for most urban meteorological applications, and can be considered for implementation in numerical weather prediction (NWP) models (e.g., Taha 1999) where its use of simple input information and its low computational cost would fit the main requirements (Loridan et al. 2010). The good performance of NARP is critical as $Q^{*}$ is the key driver for the other submodels. However, when NARP is evaluated, a nighttime bias is noticeable from some of the scatterplots (when $Q^{*}<0 \mathrm{~W} \mathrm{~m}^{-2}$ ) with a clear discontinuity in the modeled values. In the absence of incoming solar radiation, this bias directly relates to longwave radiation and, in particular, the incoming component $(L \downarrow)$.

In this paper an alternative method for $L \downarrow$ is developed with cloud data from a site in central London based on measured relative humidity and air temperature. Performance is evaluated at two independent sites (Łódź, Poland, and Baltimore, Maryland). Other new features in LUMPS allow for changing water availability at the surface, changing vegetation phenology, and anthropogenic heat. The whole LUMPS system is evaluated using an independent dataset (Łódź).

\section{Modeling incoming longwave radiation}

\section{a. The original NARP model}

In NARP (Offerle et al. 2003), $L \downarrow$ is considered to be emitted by a single-layer atmosphere with radiative properties satisfying the Stefan-Boltzmann law:

$$
L \downarrow=\varepsilon_{\text {sky }} \sigma T_{\text {sky }}^{4},
$$

where $\sigma$ is the Stefan's constant $\left(\mathrm{W} \mathrm{m}^{-2} \mathrm{~K}^{-4}\right)$ and $T_{\text {sky }}$ is the bulk atmospheric temperature, approximated by measured $T_{a}(\mathrm{~K})$. The sky emissivity $\varepsilon_{\text {sky }}$ is based on Prata's (1996) clear-sky $\varepsilon_{\text {clear }}$, which is corrected to account for the radiative impacts of clouds:

$$
\begin{aligned}
\varepsilon_{\text {clear }} & =1-(1+w) e^{-\sqrt{1.2+3 w}} ; \quad w=46.5\left(e_{a} / T_{a}\right) \\
\varepsilon_{\text {sky }} & =\varepsilon_{\text {clear }}+\left(1-\varepsilon_{\text {clear }}\right) F_{\text {CLD }}^{2},
\end{aligned}
$$

where $w$ is the precipitable water content $\left(\mathrm{g} \mathrm{cm}^{-2}\right)$ and $F_{\text {CLD }}$ represents the portion of the sky covered by clouds $\left(0<F_{\mathrm{CLD}}<1\right)$. In NARP, $F_{\mathrm{CLD}}$ is estimated from the ratio of measured $K \downarrow$ and the theoretical clear-sky value at the location $\left(K_{\text {clear }}\right)$. This is obtained from (Crawford and Duchon 1999)

$$
F_{\mathrm{CLD}}\left(K \downarrow, K_{\text {clear }}\right)=1-\frac{K \downarrow}{K_{\text {clear }}} ; \quad K_{\text {clear }}=I_{\mathrm{EX}} \cos (Z) \tau,
$$


where $I_{\mathrm{EX}}$ is the extraterrestrial (or "top" of the atmosphere) insolation, $Z$ is the solar zenith angle, and $\tau$ is the atmospheric transmissivity parameterized from measured surface pressure, temperature, and relative humidity to represent the combined effects of Rayleigh scattering, absorption by permanent gases and water vapor, and absorption-scattering by aerosols.

Such a representation of cloud coverage is not applicable at low sun elevation angles (Offerle et al. 2003; Lindberg et al. 2008) and is obviously not applicable at night. As a consequence, the original NARP only computes $F_{\mathrm{CLD}}$ for $Z<80^{\circ}$, and keeps a constant value from sunset to sunrise. The use of Smith's (1966) empirical relation in the computation of the atmospheric transmissivity $\tau$ in (4) (Crawford and Duchon 1999) is a limitation on the application of NARP as it involves latitude-dependent coefficients only available for the Northern Hemisphere that are not time sensitive.

\section{b. Cloud and radiation data from central London}

Here, $F_{\mathrm{CLD}}$ is parameterized using cloud height and cover data from a Vaisala CL31 ceilometer (Vaisala Oyj 2006), situated at King's College London $\left(51.511^{\circ} \mathrm{N}\right.$, $\left.0.116^{\circ} \mathrm{W}\right)$. The instrument consists of a low-powered, eye-safe, single-wavelength $\left(910 \pm 10 \mathrm{~nm}\right.$ at $\left.25^{\circ} \mathrm{C}\right)$ laser that samples the volume of air directly above the instrument, returning the height-normalized optical volume backscatter intensity of the atmosphere using the lidar principle (Emeis et al. 2004). The CL31 uses a high laser pulse repetition frequency of $10 \mathrm{kHz}$ to cancel noise (Eresmaa et al. 2006). Cloud information and a backscatter profile are generated every $15 \mathrm{~s}$ from samples taken every $67 \mathrm{~ms}$ for $50 \mu$ s to give a vertical profile resolution of $10 \mathrm{~m}$ up to an altitude of $7.7 \mathrm{~km}$. An inbuilt cloud detection algorithm provides cloud-base level information for up to three heights (dependent on signal extinction due to cloud thickness). By postprocessing the cloud-height data, it is possible to compute the cloud cover $\left(F_{\mathrm{CLD}}\right)$ using data from before and after each particular measurement. Each profile (every $15 \mathrm{~s}$ ) was classified as being either cloudy $\left(C_{b}=1\right)$ or clear $\left(C_{b}=\right.$ $0)$. To best represent the cloud cover influence on $L \downarrow$, a 900 -s time window (450 s before and after each measurement) was used to calculate the mean cloud cover for each particular measurement:

$$
F_{\mathrm{CLD}}(t)=\frac{1}{2 t_{w}}\left[\sum_{t=-t_{w}}^{t_{w}} C_{b}(t)\right],
$$

where $F_{\mathrm{CLD}}$ is cloud cover fraction at measurement time $t$ and $t_{w}$ is the time window expressed as a number of measurements; in the current analysis $t_{w}=30$.
In addition, a Kipp and Zonen CNR1 radiometer and a Vaisala WXT510 weather transmitter (temperature, humidity, pressure) were mounted on a tower (site name KSK) located $48.1 \mathrm{~m}$ above sea level. The 500-m-radius circle around the tower has a mean building height of $20.7 \pm 7.8 \mathrm{~m}$ and plan area fractions of building $=33.9 \%$, impervious $=34.4 \%$, and water $=26 \%$ (with the remaining fraction composed of grass, shrubs, and nonconiferous trees).

\section{c. A new parameterization of cloud impact on $L \downarrow$}

A requirement for inclusion within LUMPS is that the meteorological inputs are easily procurable, which is a central issue for most meteorological preprocessors (e.g., in dispersion modeling). Based on both common data availability and physical considerations, a set of possible predictors is initially identified. It includes the air temperature (K), relative humidity (\%), vapor pressure, and vapor pressure deficit $(\mathrm{hPa})$, as well as the precipitable water content $\left(\mathrm{g} \mathrm{cm}^{-2}\right)$, the specific humidity $\left(\mathrm{kg} \mathrm{kg}^{-1}\right)$, and the cooling rate of the air $\left(\mathrm{K} \mathrm{s}^{-1}\right)$. An improved forward stepwise selection process [least angle regression; Bradley et al. (2004)] is used to identify the predictors that demonstrate the largest correlation with the processed $F_{\text {CLD }}$ data (section 2a), to sort the quantities best able to explain cloud coverage for the period 1 July 2008-30 June 2009 in London. Least angle regression does not require the predictors to be independent of each other. The first predictor selected from such analysis is relative humidity (RH), followed by air temperature $\left(T_{a}\right)$, suggesting that the formulation for $F_{\mathrm{CLD}}$ should be primarily based on $\mathrm{RH}$ and could potentially gain from using $T_{a}$ as a complementary source of information.

A locally weighted polynomial regression procedure [locally weighted scatterplot smoothing (lowess); Cleveland 1981)] was applied to the hourly averaged $F_{\mathrm{CLD}}$ and RH measurements (Fig. 1) to identify the dominant trend. With nonlinear regression, the lowess curve is approximated by

$F_{\mathrm{CLD}}(\mathrm{RH})=A e^{B \times \mathrm{RH}} ; \quad A=0.185, \quad B=0.017$.

Repeating this for each temperature range, the influence of $T_{a}$ on $A$ and $B$ can be studied. To represent the evolution of the nonlinear regression curve, $B$ is allowed to evolve as a function of $T_{a}$ while $A$ is kept at 0.185 . The following relation is fitted through the $B$ coefficient values to allow for the $T_{a}$ dependency:

$$
B\left(T_{a}\right)=0.015+1.9 \times 10^{-4} T_{a} .
$$

Physically, this translates the idea that for a given RH the water vapor concentration of the air is higher at 


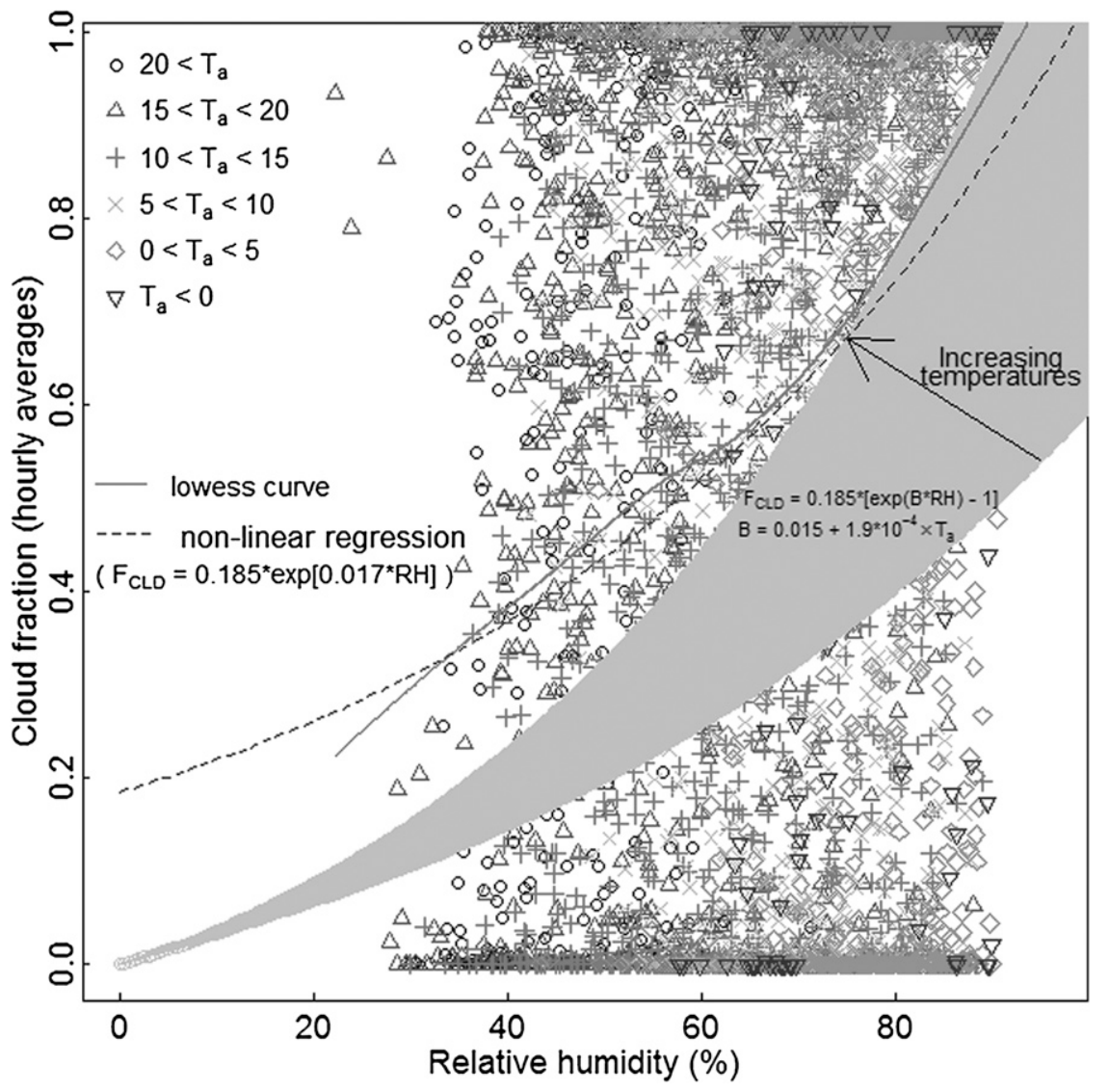

FIG. 1. Hourly cloud fraction value as a function of the RH in air temperature classes for $1 \mathrm{Jul}$ 2008-30 Jun 2009 in London. See text for explanation of the lines.

warm temperatures than it would be for cooler ones (i.e., the Clausius-Clapeyron principle) making longwave absorption-emission more likely. To avoid systematic biases at very low humidity levels (e.g., $F_{\mathrm{CLD}} \neq$ 0 if $\mathrm{RH}=0$ ), the parameterization is forced through the origin. The resulting temperature-dependent family of functions is plotted in Fig. 1 and is defined as

$$
F_{\mathrm{CLD}}\left(\mathrm{RH}, T_{a}\right)=0.185\left[e^{\left(0.015+1.9 \times 10^{-4} T_{a}\right) \times \mathrm{RH}}-1\right] .
$$

Finally, as in Crawford and Duchon (1999), $F_{\mathrm{CLD}}$ is not squared [cf. with Eq. (3)], yielding this parameterization for $L \downarrow$ :

$$
\begin{aligned}
L \downarrow\left(e_{a}, T_{a}, \mathrm{RH}\right)= & \left\{\varepsilon_{\text {clear }}\left(e_{a}, T_{a}\right)+\left[1-\varepsilon_{\text {clear }}\left(e_{a}, T_{a}\right)\right]\right. \\
& \left.\times F_{\mathrm{CLD}}\left(\mathrm{RH}, T_{a}\right)\right\} \times \sigma T_{a}^{4} .
\end{aligned}
$$

Having removed the latitude-dependent calculation of $K_{\text {clear }}$, and with $e_{a}, T_{a}$, and $\mathrm{RH}$ as the only inputs, this empirical $L \downarrow$ model offers the advantage of an easy implementation within LUMPS and is applicable to any hour of the day.
Additionally, the use of observed $F_{\mathrm{CLD}}$ rather than modeled $F_{\mathrm{CLD}}$ is considered. This requires more input but the added accuracy should greatly improve $L \downarrow$. If such data are not available directly at the desired location, they can be obtained from the fraction of sky coverage typically observed at the nearest airport and archived by the National Climatic Data Center (NCDC 2009). Coverage in 10ths is used for $F_{\mathrm{CLD}}$ in

$$
\begin{aligned}
L \downarrow\left(e_{a}, T_{a}, \mathrm{NCDC}\right)= & \left\{\varepsilon_{\text {clear }}\left(e_{a}, T_{a}\right)\right. \\
& +\left[1-\varepsilon_{\text {clear }}\left(e_{a}, T_{a}\right)\right] \\
& \left.\times F_{\mathrm{CLD}}(\mathrm{NCDC})\right\} \times \sigma T_{a}^{4} .
\end{aligned}
$$

\section{d. Evaluation of the new incoming longwave radiation model}

The $L \downarrow$ model in Eq. (9) is evaluated using data from two independent sites (Grimmond et al. 2002; Offerle et al. 2006): Cub Hill in Baltimore $\left(39.41^{\circ} \mathrm{N}, 76.52^{\circ} \mathrm{W}\right.$ ) and Lipowa in Łódź $\left(51.75^{\circ} \mathrm{N}, 19.46^{\circ} \mathrm{E}\right)$. In addition, the original version that uses $K \downarrow$ and $K_{\text {clear }}$ [Eqs. (3) and (4)], and the simplified one requiring observed $F_{\text {CLD }}$ 
data [Eq. (10)], are applied to permit direct performance comparison. Apart from the different synoptic conditions and geographical locations characterizing them, the two sites are selected because of their multiyear datasets and, hence, wide seasonal conditions. Radiation components ( $K \downarrow, K \uparrow, L \downarrow$, and $L \uparrow)$ were obtained using a Kipp and Zonen CNR1, $T_{a}$, RH (Campbell Scientific 500, Baltimore and Rotronic MP100H, Łódź), and station pressure (Vaisala PTB101B, Baltimore; PTA427, Łódź). The measurement periods used are 24 May 200131 December 2006 for Baltimore and November 200031 December 2002 for Łódź. In Łódź, observations of turbulent and storage heat fluxes are used to evaluate the ability of LUMPS to simulate the urban SEB (see section 3).

With the exception of $F_{\mathrm{CLD}}$, the required inputs are available from measurements at the same location as $L \downarrow$. The observed $F_{\text {CLD }}$ were obtained from NCDC for Baltimore-Washington International Airport and Łódź's Wladyslaw Reymont Airport. Time periods with data gaps in either $T_{a}, \mathrm{RH}$, or $F_{\mathrm{CLD}}(\mathrm{NCDC})$ are excluded from the analysis $(17.2 \%$ of the periods excluded for BA01-BA06 and $17.4 \%$ for LO01 and LO02).

To evaluate the performance of the four approaches, the root-mean-square errors (RMSE) and mean bias error (MBE) are used with scatter- and box plots (Fig. 2). The fourth alternative obtains $F_{\mathrm{CLD}}$ by Eq. (4) when $Z \leq$ $80^{\circ}$; otherwise, Eq. (8) is used (Fig. 2d). For the first complete year at Baltimore (2002, hereinafter BA02) there are similar overall RMSE results $\left(\sim 30 \mathrm{~W} \mathrm{~m}^{-2}\right)$ for approaches that model $F_{\mathrm{CLD}}$ (Figs. 2a, 2b, and 2d). The original $F_{\mathrm{CLD}}\left(K \downarrow, K_{\text {clear }}\right)$ performs best during the daytime $\left(1.1 \mathrm{~W} \mathrm{~m}^{-2}\right.$ smaller RMSE; day $\left.Z \leq 80^{\circ}\right)$ and the new $F_{\text {CLD }}\left(\mathrm{RH}, T_{a}\right)$ best at night $\left(1.7 \mathrm{~W} \mathrm{~m}^{-2}\right.$ smaller RMSE; night $\mathrm{Z}>80^{\circ}$ ). However, linear regression shows a noticeable negative bias relative to the 1:1 line with the $F_{\mathrm{CLD}}(K \downarrow$, $K_{\text {clear }}$ ) (Fig. 2b), suggesting a significant tendency to underestimate $L \downarrow$. This is confirmed by the overall, day and night negative $\operatorname{MBEs}\left(-15,14\right.$, and $\left.-15 \mathrm{~W} \mathrm{~m}^{-2}\right)$ and the box-plot medians. For the new $F_{\mathrm{CLD}}\left(\mathrm{RH}, T_{a}\right)$, all of the MBE are improved $\left(-0.4,-4.2\right.$, and $\left.2.9 \mathrm{~W} \mathrm{~m}^{-2}\right)$ and the linear regression (close to the 1:1 line) confirms very few biases. The interquartile range (IQR) for the observed values of $L \downarrow$ in the range $280-350 \mathrm{~W} \mathrm{~m}^{-2}$ is larger but with fewer outliers. The combined method slightly outperforms the other two in terms of RMSE ( $\leq 1 \mathrm{~W} \mathrm{~m}^{-2}$ smaller) but both its negative overall $\mathrm{MBE}$ value $\left(-4.9 \mathrm{~W} \mathrm{~m}^{-2}\right)$ and the linear regression line confirm it has inherited the tendency to underestimate $L \downarrow$ from the original daytime formulation. As expected, use of NCDC $F_{\text {CLD }}$ data yields the best performance with the lowest RMSE ( $\geq 6.5 \mathrm{~W} \mathrm{~m}^{-2}$ smaller), no significant biases identified, and the smallest IQRs (Fig. 2c).
A similar pattern is found for the other Baltimore datasets (BA01 and BA03) and Łódź (LO01 and LO02) with systematically lower biases from the new $F_{\mathrm{CLD}}\left(\mathrm{RH}, T_{a}\right)$ (improvements in $|\mathrm{MBE}|$ of 3.9 in BA01, 16.9 in BA03, and $8.5 \mathrm{~W} \mathrm{~m}^{-2}$ in both LO01 and LO02) and comparable overall RMSEs (within $\pm 2 \mathrm{~W} \mathrm{~m}^{-2}$ overall RMSE difference for BA01-BA03 and LO01 and LO02; see Fig. 3). Only BA06 shows a larger bias $\left(7.3 \mathrm{~W} \mathrm{~m}^{-2}\right.$ larger overall $|\mathrm{MBE}|$, and a switch to positive) and significantly poorer RMSE (5.7 $\mathrm{W} \mathrm{m}^{-2}$ larger overall RMSE) from the new model. The best improvement is obtained for the BA04 and BA05 datasets when the RMSEs are consistently lower [5.7 (4.1) $\mathrm{W} \mathrm{m}^{-2}$ reduction in overall RMSE for BA04 (BA05)]. In most cases, the added value of a parameterization that is applicable $24 \mathrm{~h} \mathrm{day}^{-1}$ is clearly noticeable from the nighttime RMSE. The 4th alternative, the combination of two $F_{\text {CLD }}$ models, is not shown as it can be inferred from the other RMSE statistics. In all situations, using observed rather than modeled $F_{\mathrm{CLD}}$ [Eq. (10)] provides the best performance (overall 5-7 $\mathrm{W} \mathrm{m}^{-2} \mathrm{RMSE}$ smaller than the second-best option).

To investigate the impacts of seasonality, the Baltimore and Łódź 2002 datasets are split into December-February (DJF), March-May (MAM), June-August (JJA), and September-November (SON) (Fig. 4). The $F_{\mathrm{CLD}}(K \downarrow$, $\left.K_{\text {clear }}\right)$ has a systematic negative MBE in $L \downarrow$ for all seasons $\left(-23.4 \leq \mathrm{MBE} \leq-6.7 \mathrm{~W} \mathrm{~m}^{-2}\right)$, whereas using $F_{\mathrm{CLD}}\left(\mathrm{RH}, T_{a}\right)$ there is a switch from negative to positive MBEs $\left(-17.5 \leq \mathrm{MBE} \leq 14.7 \mathrm{~W} \mathrm{~m}^{-2}\right)$ when moving toward the summer (JJA). This is linked to the temperature formulation (7) selected to modulate the $F_{\mathrm{CLD}}(\mathrm{RH})$ relation (Fig. 1); although designed to account for the temperature influence on $\mathrm{RH}$, the range of $T_{a}$ values used for the model development with observation from the London site $\left(-3.5^{\circ} \mathrm{C} \leq T_{a} \leq 28.7^{\circ} \mathrm{C}\right)$ is not as wide as the one occurring during BA02 $\left(-14.5^{\circ} \mathrm{C} \leq T_{a} \leq 33.6^{\circ} \mathrm{C}\right)$ and $\mathrm{L} 002\left(-17.5^{\circ} \mathrm{C} \leq T_{a} \leq 30.8^{\circ} \mathrm{C}\right)$. Unexpectedly low (high) biases might therefore occur at very cold (warm) temperatures. For the RMSE, no clear evolution is identified but the poorer overall performance of the $F_{\mathrm{CLD}}\left(\mathrm{RH}, T_{a}\right)$ model during the SON period for both sites and during DJF for Łódź are noted.

Mean diurnal plots by season, for the two sites (Fig. 5), confirm the switch in bias from an underestimation of $L \downarrow$ in winter to its overestimation in summer from $F_{\mathrm{CLD}}\left(\mathrm{RH}, T_{a}\right)$. Most importantly the plots highlight the discontinuities inherent in a $F_{\mathrm{CLD}}$ based on $K \downarrow$ : a poor nighttime approximation and strong discontinuities at low sun elevation angles. A systematic daytime underestimation is also clearly noticeable. This is linked to the squared $F_{\mathrm{CLD}}$ term in Eq. (3), which directly reduces the contribution of cloud coverage to the modeled $L \downarrow$. This supports use of the original Crawford and Duchon 

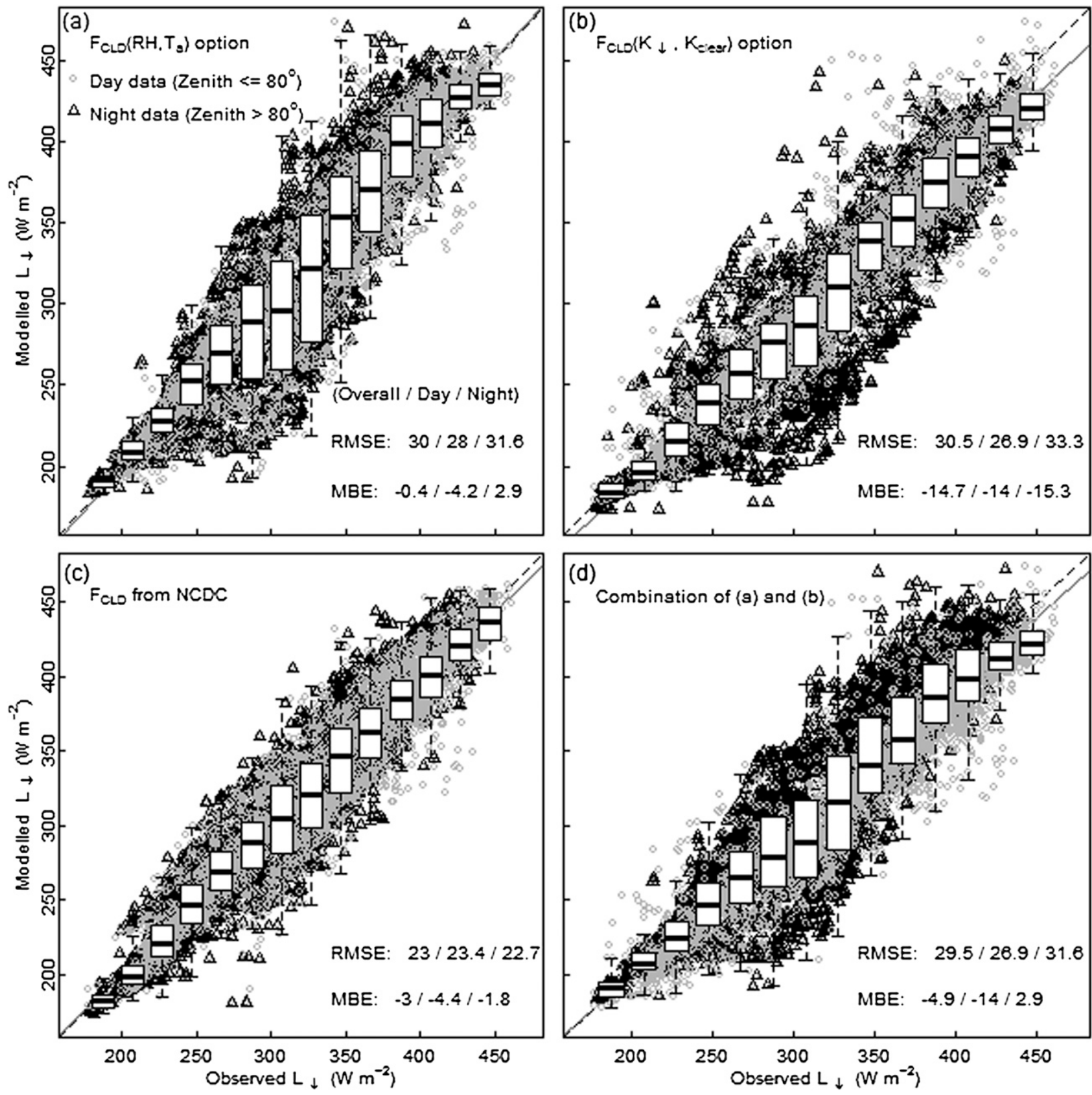

FIG. 2. Observed vs modeled $L \downarrow$ for Baltimore during 2002 with cloud fraction based on (a) Eq. (8), (b) Eq. (4), (c) NCDC observations, and (d) Eqs. (8) and (4), depending on the solar zenith angle value (see text). The all-hours-day-night RMSEs and MBEs (W $\mathrm{m}^{-2}$ ) for the period, and the linear regression (solid) and 1:1 (dashed) lines are shown. Box plots are for $20 \mathrm{~W} \mathrm{~m}^{-2}$ bins of the observed data.

(1999) formulation without the squared contribution as preferable.

The main conclusion from this independent evaluation is that observed cloud data are preferred to any of the modeling options, even if they are only available from a nearby site (e.g., at the nearest airport). The NCDC database used in this study covers the entire globe (NCDC 2009). If such data are not available, or have gaps, then the newly developed $F_{\mathrm{CLD}}\left(\mathrm{RH}, T_{a}\right)$ option has fewer systematic biases and is more easily applied globally. The other options considered here are included in LUMPS to provide more flexibility for the user but are not recommended as a default setting.

\section{Flux modeling with LUMPS}

\section{a. Overview of the model}

LUMPS (Grimmond and Oke 2002) and NARP (Offerle et al. 2003) are combined here. When provided with an estimate of the incoming solar radiation $(K \downarrow$, 


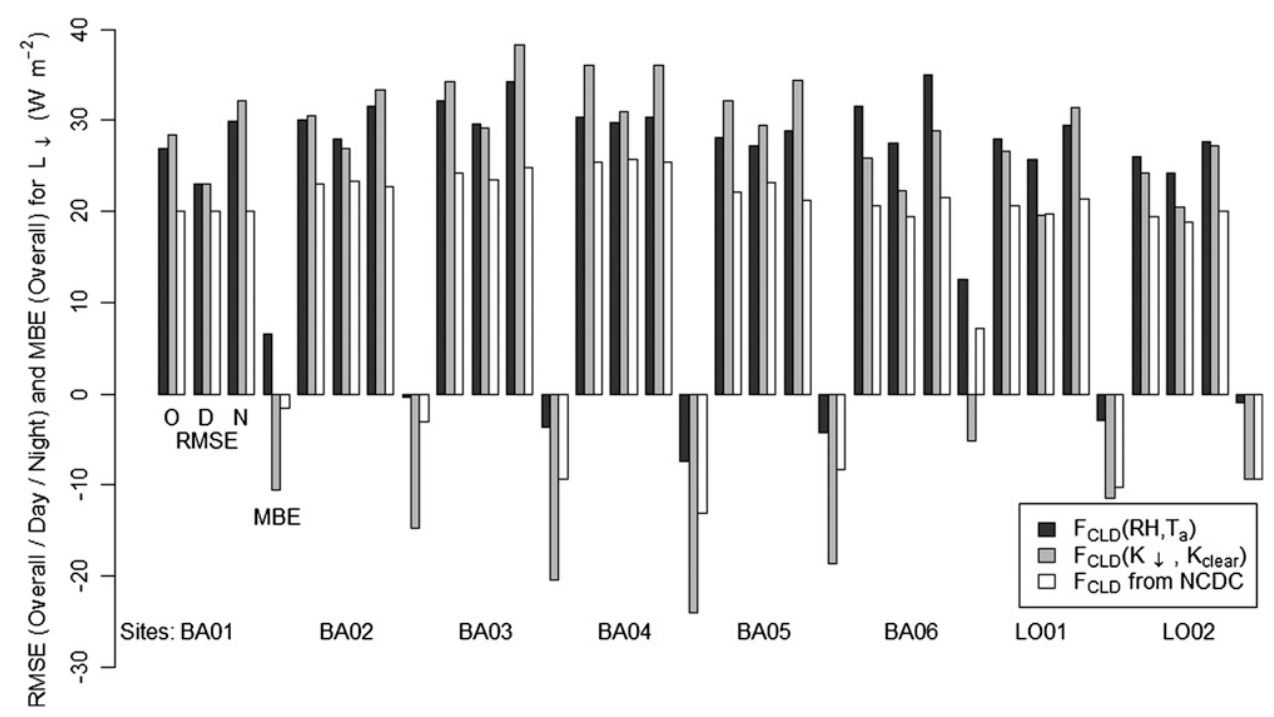

FIG. 3. The RMSE (analyzed for all-daytime-nighttime hours) and MBE (all hours only) when modeling $L \downarrow$ for Baltimore (2002-06, BA01-BA06) and Łódź (2001-02, LO01 and LO02) using options (a),(b), and (c) given in Fig. 2.

observed), incoming longwave radiation ( $L \downarrow$, observed or modeled), near-surface air temperature $\left(T_{a}\right.$, observed) and bulk radiative properties of the surface $\left(\alpha_{0}, \varepsilon_{0}\right.$, estimated from observations or field survey), NARP is able to compute the net all-wave radiation flux $Q^{*}$, which controls the magnitude of the modeled SEB Eq. (1):

$$
Q^{*}=K \downarrow\left(1-\alpha_{0}\right)+\varepsilon_{0}\left(L \downarrow-\sigma T_{a}^{4}\right)-0.08 K \downarrow\left(1-\alpha_{0}\right) .
$$

The final term on the right-hand side of Eq. (11) is included to correct for the differences between the radiative temperature of the surfaces and the near-surface temperature $T_{a}$ by which they are approximated here
[Holtslag and van Ulden (1983); van Ulden and Holtslag (1985); see discussion of Eq. (16) in Offerle et al. (2003)].

Five options are implemented in LUMPS for $L \downarrow$ :

1) provided by the user from either observations or the output of an NWP model at a similar scale; local observations are preferred as they are the most accurate;

2) modeled from Eq. (10) using observations of cloud fraction (e.g., NCDC);

3) modeled using Eq. (9), without any further input requirement;

4) modeled as in Offerle et al. (2003); and

5) modeled by combining options 3 and 4 (i.e., as in Fig. 2d).

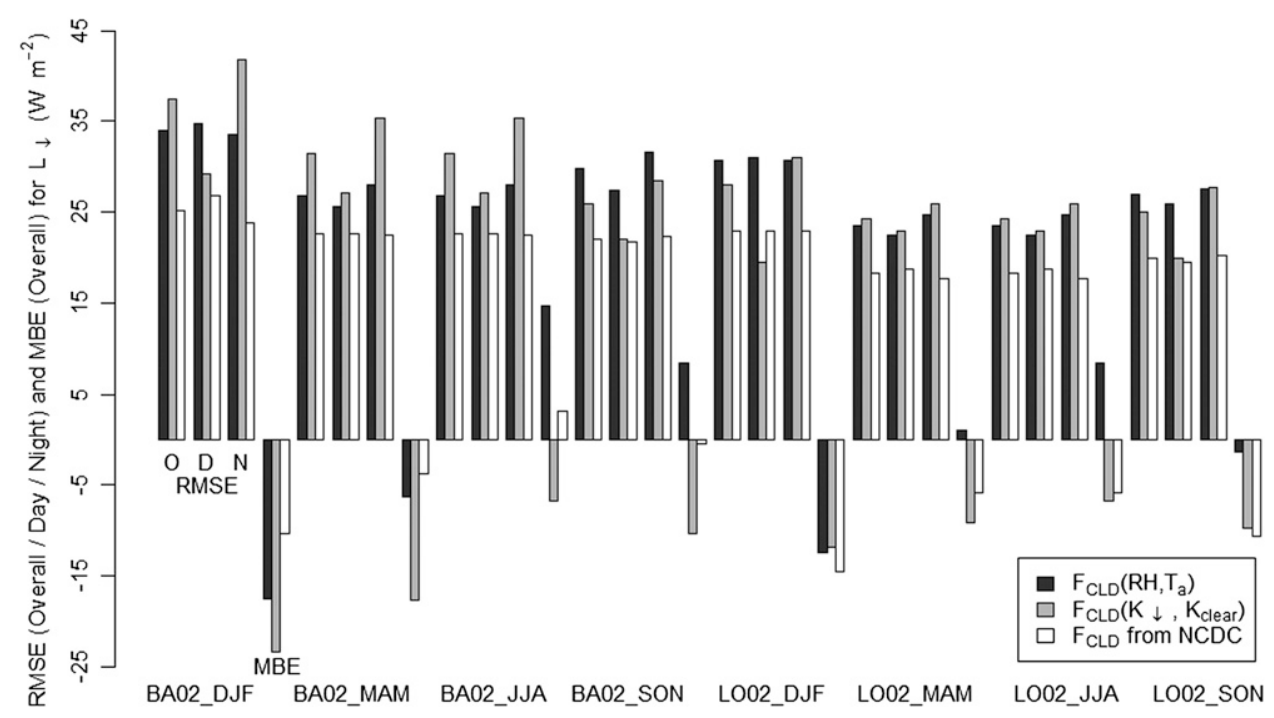

FIG. 4. As in Fig. 3, but for DJF, MAM, JJA, and SON 2002. 

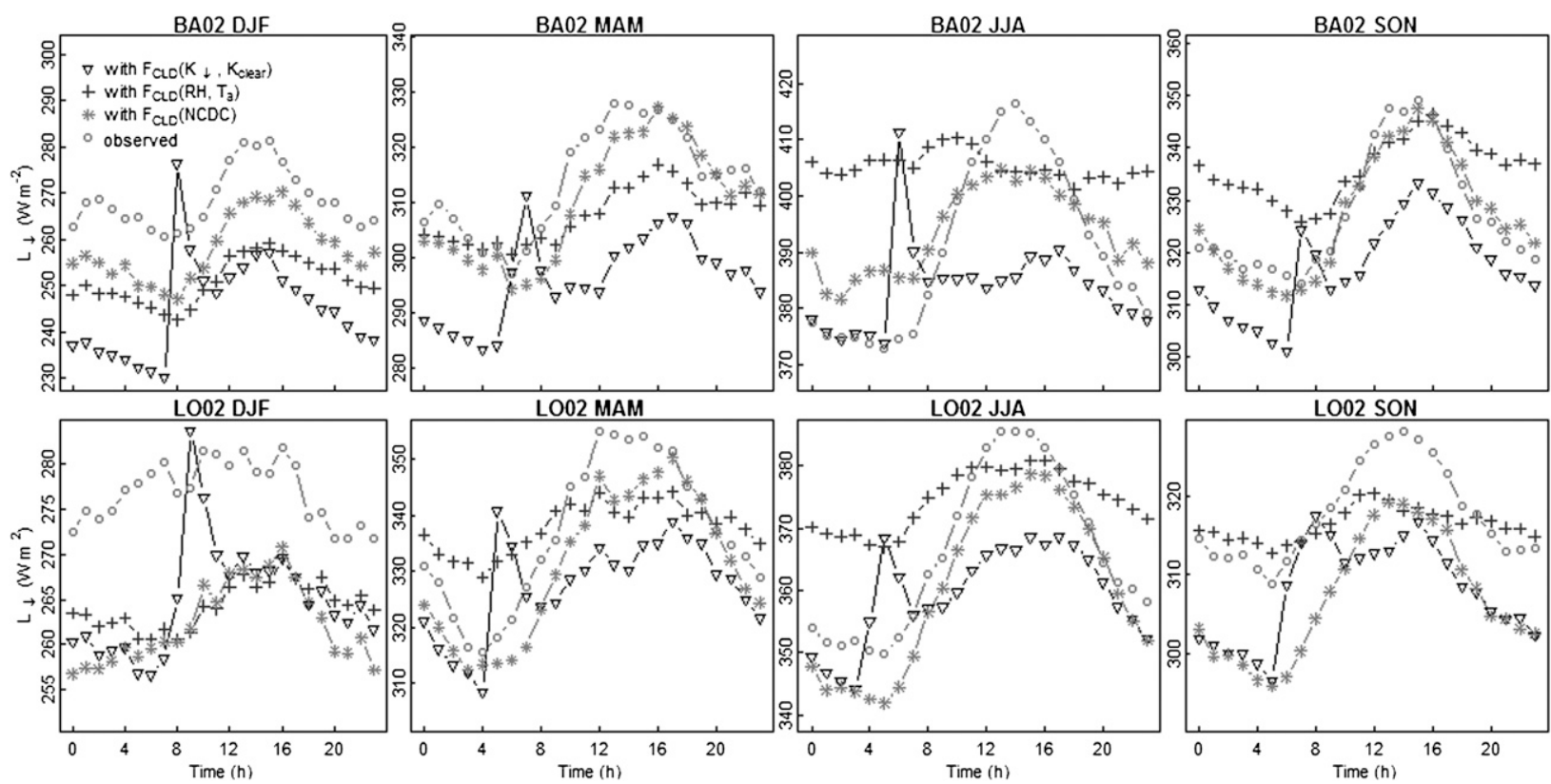

FIG. 5. Diurnal mean observed and modeled $L \downarrow$ for the same seasons as in Fig. 4. See text or Fig. 2 for details on model options.

Options 3-5 have equivalent input requirements but option 3 is more widely applicable (section 2 ; not restricted to the Northern Hemisphere, applicable $24 \mathrm{~h} \mathrm{day}^{-1}$ ).

The second submodel in LUMPS, the OHM of Grimmond et al. (1991) for storage heat $\left(\Delta Q_{S}\right)$, is a function of $Q^{*}$ and its first-order derivative [Grimmond and Oke's (2002) Eq. (2)]. The user specifies $n$ surface types, which characterize the fraction area cover $\left(f_{i}\right)$ and the appropriate coefficients [see Table 1 in Grimmond and Oke (2002) and Table 4 in Meyn and Oke (2009)]. As it requires $Q^{*}, \Delta Q_{S}$ will suffer from any bias in $L \downarrow$.

The available energy $\left(Q^{*}-\Delta Q_{S}\right)$ and land cover characteristics control the turbulent fluxes of heat and moisture following a modified combination approach [de Bruin and Holtslag (1982); Grimmond and Oke (2002), their Eqs. (3) and (4)]. The partitioning coefficients $(\alpha, \beta)$ are calculated based on the vegetation fractions (Grimmond and Oke 2002, see their Table 5). An increase of $\alpha$ (representing additional moisture) would directly enhance $Q_{E}$ while limiting $Q_{H}$. Any error in $L \downarrow$ will cascade through from $Q^{*}$ to $\Delta Q_{S}$ and the turbulent fluxes $Q_{H}$ and $Q_{E}$.

The new developments to LUMPS allow runs through the seasons and synoptic weather conditions. First, a surface water balance is implemented as a simple bucket model. Precipitation accumulates in a reservoir of predefined capacity (e.g., res cap $=10 \mathrm{~mm}$ ). Drainage commences when accumulated water exceeds a user-defined threshold (e.g., rain cover $=0.01 \mathrm{~mm}$ ). When the surface is wet, potential evaporation occurs. When the air temperature is greater than $0^{\circ} \mathrm{C}$, the bucket is drained at a specified rate (e.g., res $_{\text {drain }}=0.25 \mathrm{~mm} \mathrm{~h}^{-1}$ ) and latent heat flux from the preceding hour is also removed from the bucket.

Second, the fraction of area that has active vegetation is allowed to vary based on vegetation phenology $(V)$, which is parameterized from a combination of growth and decay functions as shown in Eq. (12). For the Northern Hemisphere the two functions are multiplied (summed for the Southern Hemisphere):

$$
\begin{aligned}
V_{\left(d_{i}, \text { Northern hemisphere }\right)} & =\frac{1}{1+10^{k_{s}\left(d_{s}-d_{i}\right)}} \times \frac{1}{1+10^{k_{f}\left(d_{i}-d_{f}\right)}} \\
V_{\left(d_{i}, \text { Southern hemisphere }\right)} & =\frac{1}{1+10^{k_{s}\left(d_{s}-d_{i}\right)}}+\frac{1}{1+10^{k_{f}\left(d_{i}-d_{f}\right)}} \\
d_{s} & =\frac{s_{\text {start }}+s_{\text {stop }}}{2} ; \quad d_{f}=\frac{f_{\text {start }}+f_{\text {stop }}}{2} ; \quad k_{s}=\frac{\log \left(\frac{1-V_{0}}{V_{0}}\right)}{d_{s}-s_{\text {start }}} ; \quad k_{f}=\frac{\log \left(\frac{1-V_{0}}{V_{0}}\right)}{f_{\text {stop }}-d_{f}},
\end{aligned}
$$


where the days of year (DOYs) indicate the start of leafon, $s_{\text {start }}$, or leaf-off, $f_{\text {start }} ; d_{s}\left(d_{f}\right)$ is the median point of the spring (fall) period; $s_{\text {stop }}\left(f_{\text {stop }}\right)$ is the end of the spring (fall) period; and $d_{i}$ is the current DOY. Coefficients $k_{s}$ and $k_{f}$ characterize the slopes of the growth and decay curves, respectively. The transition window coefficient width $\left(V_{0}=0.03\right)$ allows for a $3 \%$ fraction of the growth (decay) to occur outside the specified window.

Third, anthropogenic heat flux is included. There are a wide range of techniques for simulating $Q_{F}$ (Kikegawa et al. 2003; Sailor and Lu 2004; Offerle et al. 2005) but our preference is for minimal input requirements. Following Pigeon et al. (2007), a parameterization based on the air temperature is implemented:

$$
\begin{aligned}
& Q_{F}\left(T_{a}<T_{c}\right)=Q_{F, \text { min }}+Q_{F, \text { slope }}\left(T_{c}-T_{a}\right) \quad \text { and } \\
& Q_{F}\left(T_{a} \geq T_{c}\right)=Q_{F, \text { min }},
\end{aligned}
$$

where $Q_{F, \text { min }}$ is the minimum anthropogenic heat, $Q_{F \text {,slope }}$ is the slope, and $T_{c}$ is the critical temperature. The coefficients in Eq. (13) will vary depending on climatic and cultural habits. One set of coefficients will account for diurnal variations in temperature but not behavioral differences (e.g., day of week, working hours). Alternatively, $Q_{F}$ values from a different source can be read in (e.g., Flanner 2009; Allen et al. 2010); $Q_{F}$ is added to $Q^{*}$ before calculating $\Delta Q_{S}$ and does not influence the outgoing longwave radiation and hence $Q^{*}$.

The model surface characteristics can be either static (fixed) or dynamic (changing each time step). The dynamic approach allows a more correct comparison with the observations as the flux footprint for each time period is used as a filter (Grimmond and Oke 1991).

\section{b. Model evaluation}

The "base run" of LUMPS (section 3a) omits $Q_{F}$ and uses static surface characteristics. Simulations are for the Lipowa site in Łódź $\left(Q^{*}, Q_{H}, Q_{E}, \Delta Q_{S}\right)$ and Cub Hill in Baltimore ( $Q^{*}$ only) for the range of $L \downarrow$ options. Measurements of the $3 \mathrm{D}$ wind velocities and virtual temperature using a sonic anemometer (Applied Technologies, model $\mathrm{K}$ type), and water vapor fluctuations from a krypton hygrometer (Campbell Scientific Inc., model $\mathrm{KH}_{2} \mathrm{O}$ ) at $37 \mathrm{~m}$ above the ground were used to calculate the turbulent sensible and latent heat fluxes (Offerle 2003; Offerle et al. 2006). The mean building height $\left(Z_{H}=10.6 \mathrm{~m}\right)$ in Łódź [see Table 3 in Offerle et al. (2006)] ensures that sensors are located above the $2 Z_{H}$ transition height (e.g., Kastner-Klein and Rotach 2004) and should therefore be representative of the local scale. The storage heat flux is estimated by using the element surface temperature method (ESTM; Offerle et al. 2005) based on measurements of wall, road (infrared thermometers), roof, and air (fast-response thermocouples) temperatures for a 6-month period in 2002 (JulyDecember). Linear regression is used with the surface temperatures from the radiation components, air temperature, and solar zenith angle to obtain a complete temperature and $\Delta Q_{S}$ dataset for the $2 \mathrm{yr}$ [Eq. (4); Offerle et al. (2005)].

The model is forced with hourly values of air temperature $\left(T_{a}\right)$, atmospheric pressure $\left(P_{a}\right)$, relative humidity (RH), incoming solar radiation $(K \downarrow)$, and precipitation rate. Hourly observations of $L \downarrow$ are provided for option 1 and cloud fraction from NCDC for option 2. Input parameter values used for the Łódź runs are given in Table 1. Data gaps in the input variables (i.e., $T_{a}$, RH, $F_{\text {CLD }}(\mathrm{NCDC})$, or $\left.L \downarrow\right)$ were filled to allow LUMPS to run continuously but these periods are excluded from the evaluation.

The choice of an appropriate model is dependent on the application. Consideration needs to be given to the variables to which a model must have small tolerance of error (or greatest capability). Baklanov et al. (2009) discuss five applications: air quality exposure studies, urban climate studies and development of strategies to mitigate the intensity of heat islands, emergency response pathways for toxic gas releases, forecasting air quality and weather, and urban planning. These require different fluxes and variables (e.g., wind speed, wind direction, temperature, humidity, pollutant concentration, turbulent fluxes) to be correct and/or have different levels of tolerance at different times of the day. For example, meteorological preprocessors for air quality and dispersion have the estimation of $Q_{H}$ as a major goal, for their ultimate use in estimating Obukhov length and turbulent motions. For that use, a 10 or $20 \mathrm{~W} \mathrm{~m}^{-2}$ error in $Q_{F}$ at night may have major unwanted consequences, such as shifting the stability from stable to unstable or vice versa. However, for estimating the surface heat fluxes with an NWP model, the $Q_{H}$ accuracy at night may not be so important. Here, we do not assess the performance for a particular application. Thus, there is no desired or required accuracy beyond the ideal of zero model error.

\section{1) Net all-wave Radiation}

Simulations of $Q^{*}$ with $L \downarrow$ options 1-4 for the LO02 and BA03 datasets are plotted (Fig. 6) and statistics for all eight datasets are computed (Table 2). Option 5 is not shown. As expected, the use of observed $L \downarrow$ yields the best performance in all cases, with the overall RMSE from 3.7 to $13.4 \mathrm{~W} \mathrm{~m}^{-2}$ better than the second-best option. Option 2 is arguably second best, with lower RMSEs in most cases and good agreement between the linear regression and 1:1 lines (e.g., Fig. 6b $b_{1}$ ); however, this option tends to overestimate $Q^{*}\left(\mathrm{MBE}>10 \mathrm{~W} \mathrm{~m}^{-2}\right)$. 
TABLE 1. LUMPS model parameters assigned for the Łódź runs (2001-2002). Note that $Q_{F}$ was initially not included in the base run.

\begin{tabular}{|c|c|}
\hline Model input parameters & Values assigned for Łódź runs \\
\hline Bulk albedo $\left(\alpha_{0}\right)$, emissivity $\left(\varepsilon_{0}\right)$ & $\alpha_{0}=0.08, \varepsilon_{0}=0.92$ \\
\hline Lat, lon & Lat $=51.75^{\circ} \mathrm{N}$, lon $=19.46^{\circ} \mathrm{E}$ \\
\hline No. of surface types in OHM & $n=3$ \\
\hline Fraction cover of each surface type & $f_{\text {build }}=0.3$ buildings, $f_{\text {imp }}=0.4$ impervious, $f_{\text {veg }}=0.3$ vegetated \\
\hline OHM coefficients & $\begin{array}{l}\text { Vegetation, mixed forest (McCaughey 1985); roof, bitumen spread } \\
\text { over flat industrial membrane (Meyn and Oke 2009); impervious, } \\
\text { mean of all five concrete and asphalt sources [see Table } 4 \text { in } \\
\text { Grimmond and Oke (1999)] }\end{array}$ \\
\hline $\begin{array}{l}\text { Reservoir capacity }\left(\operatorname{res}_{\text {cap }}\right) \text {, drainage } \\
\text { rate }\left(\text { res }_{\text {drain }}\right) \text {, threshold for complete } \\
\text { surface coverage (rain cover) }\end{array}$ & $\mathrm{res}_{\mathrm{cap}}=10 \mathrm{~mm}, \mathrm{res}_{\mathrm{drain}}=0.25 \mathrm{~mm} \mathrm{~h}^{-1}$, rain cover $=0.01 \mathrm{~mm}$ \\
\hline Vegetation phenology (12) & $s_{\text {start }}=69 ; s_{\text {stop }}=144 ; f_{\text {start }}=281 ; f_{\text {stop }}=324 ; V_{0}=0.03$ \\
\hline \multirow[t]{4}{*}{$\alpha_{\text {int }}, \alpha_{\text {slope }}, \beta_{\text {int }}$, and $\beta_{\text {slope }}$} & $\alpha=\alpha_{\text {int }}+\alpha_{\text {slope }} \times f_{\text {veg }} \times V\left(d_{i}\right)$ \\
\hline & $\beta=\beta_{\text {int }}+\beta_{\text {slope }} \times f_{\text {veg }} \times V\left(d_{i}\right)$ \\
\hline & $\alpha_{\text {slope }}\left(f_{\text {veg }}>0.9\right)=0.8 ; \alpha_{\text {slope }}\left(f_{\text {veg }} \leq 0.9\right)=0.686$ \\
\hline & $\alpha_{\text {int }}=0.2 ; \beta_{\text {int }}=3 \mathrm{~W} \mathrm{~m}^{-2} ; \beta_{\text {slope }}=17 \mathrm{~W} \mathrm{~m}^{-2}$ \\
\hline Anthropogenic heat for run 2 [Eq. (13)] & $Q_{F, \text { min }}=15 \mathrm{~W} \mathrm{~m}^{-2}, Q_{F, \text { slope }}=2.7 \mathrm{~W} \mathrm{~m}^{-2}{ }^{\circ} \mathrm{C}^{-1}, T_{c}=7^{\circ} \mathrm{C}$ \\
\hline
\end{tabular}

The levels of statistical performance for options 3 and 4 are poorer, with a tendency toward an underestimation of $Q^{*}$ for option $4\left(-14 \leq \mathrm{MBE} \leq 3 \mathrm{~W} \mathrm{~m}^{-2}\right.$ with a mean of $-5.4 \mathrm{~W} \mathrm{~m}^{-2}$ over the eight datasets; negative intercept for six out of eight datasets) and overestimation for option $3\left(3 \leq \mathrm{MBE} \leq 14 \mathrm{~W} \mathrm{~m}^{-2}\right.$ with a mean of $7.4 \mathrm{~W} \mathrm{~m}^{-2}$ ). The nighttime bias from option 4 , with a clear discontinuity for low $Q^{*}$ values, is best seen from Fig. $6 d_{2}$ (also Fig. $6 d_{1}$ ). Option 3 does not have such a discontinuity, although the scattering of points is higher than for option 1 for low $Q^{*}$ values (Fig. 6c).

\section{2) IMPACTS ON ALl SURFACE ENERGY BALANCE FLUXES}

All fluxes modeled in LUMPS are explicitly linked to $Q^{*}$. The overall errors for $Q_{H}$ and $\Delta Q_{S}$ are $30 \leq \mathrm{RMSE} \leq$ $43 \mathrm{~W} \mathrm{~m}^{-2}$, for all options and seasons, and for $Q_{E}$ they are $22 \leq \mathrm{RMSE} \leq 33 \mathrm{~W} \mathrm{~m}^{-2}$. The ability to model the diurnal cycle varies with season. The daytime maximum value of the mean measured $Q_{H}$ flux, for instance, varies between 65 in winter and $>200 \mathrm{~W} \mathrm{~m}^{-2}$ in spring, but the RMSE only vary from 33 to $40 \mathrm{~W} \mathrm{~m}^{-2}$ for the four options (Fig. 7). Although LUMPS is simple, it is able to reproduce the main aspects of the surface-atmosphere energy exchange in urban areas, including both its diurnal and seasonal variabilities. Note that for all fluxes except $Q^{*}$, the levels of RMSE performance for the four $L \downarrow$ options are within $\pm 4 \mathrm{~W} \mathrm{~m}^{-2}$.

For $Q^{*}, L \downarrow$ option 2 consistently leads to the highest daytime maximum for all seasons and is the only option to overestimate the observed maximum value in most cases whereas option 4 tends to underestimate such daytime maxima for all periods except DJF (Fig. 7a). Nighttime levels of performance vary considerably from one season to the other. Option 4 underestimates $Q^{*}$ in the hours preceding sunrise in most cases (e.g., Fig. 7a) but appears to be reasonable in the early hours of the night. Option 3 has a tendency to overestimate the observed nighttime $Q^{*}$ values and closely follows option 2 . Option 1 is closest to the observations in most cases. In terms of RMSE, option 1 is by far the most accurate choice $\left(6 \leq \mathrm{RMSE} \leq 11 \mathrm{~W} \mathrm{~m}^{-2}\right)$ while the other three options are more comparable. In terms of MBE, options 1-3 exhibit positive biases for all seasons, with the highest value to be found for option 2 in MAM (MBE = $20 \mathrm{~W} \mathrm{~m}^{-2}$ ), while option 4 has negative biases from September to February.

The direct link between $Q^{*}$ and $\Delta Q_{S}$ through OHM is apparent from the relative levels of performance of the four options (Figs. 7e-h), where those with higher (lower) $Q^{*}$ values also generate higher (lower) storage (see overall MBE statistics). The discrepancies are attributed to OHM not accounting for all the processes involved in the determination of $\Delta Q_{S}$. The influence of seasonality on the performance is clear (Fig. 7), with a noticeable underestimation during winter $(-20 \leq$ $\left.\mathrm{MBE} \leq-16 \mathrm{~W} \mathrm{~m}^{-2}\right)$ and an overestimation in summer $\left(19 \leq \mathrm{MBE} \leq 24 \mathrm{~W} \mathrm{~m}^{-2}\right)$. Patterns of anthropogenic energy usage, the frequency of rain episodes (with water runoff absorbing heat from the surface and transporting it out of the system), the decrease in storage efficiency at high wind speeds, or the variability in turbulent heat exchange when the prevailing wind direction changes (hence leading to different fetch characteristics) are 

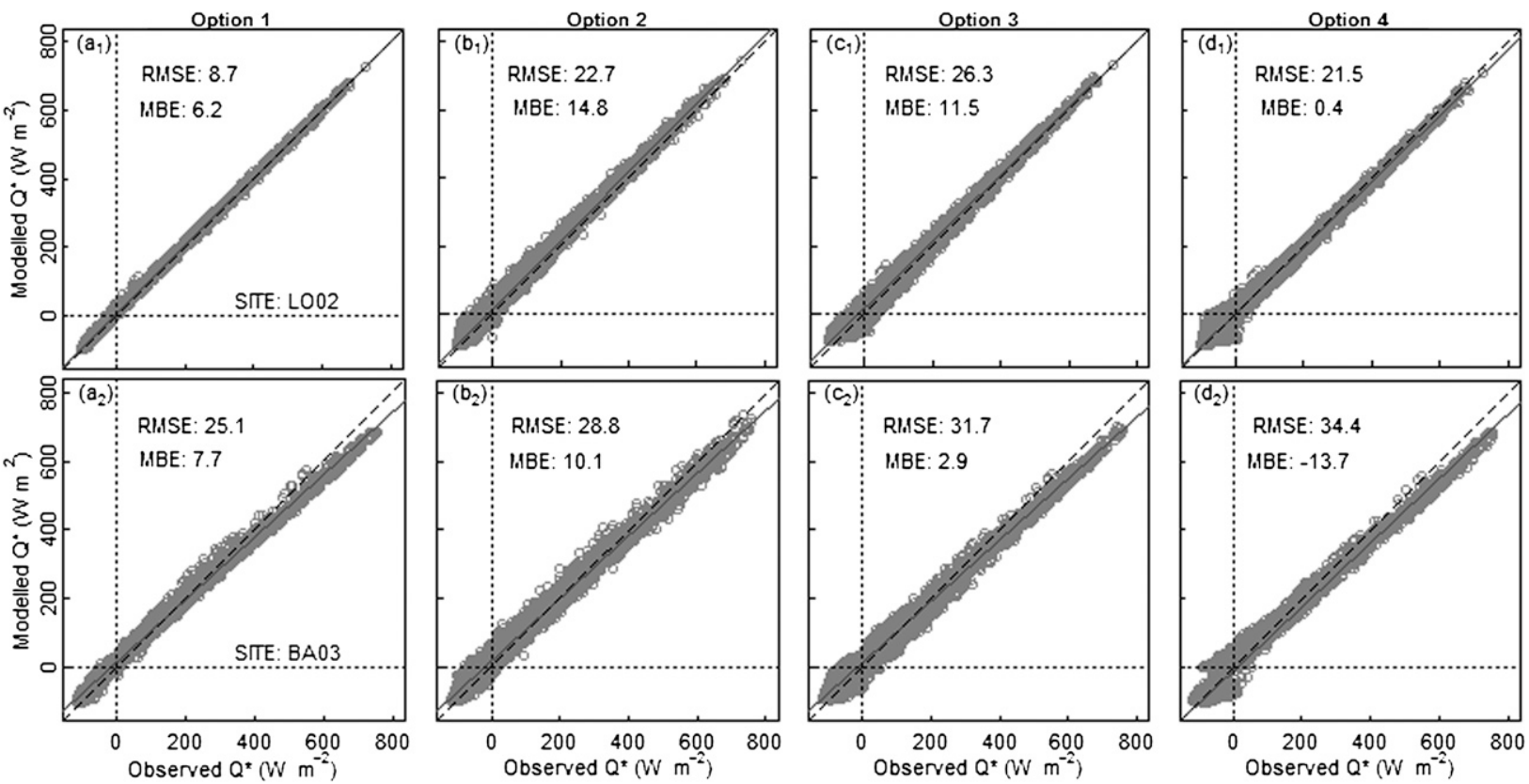

FIG. 6. Observed vs modeled net all-wave radiation $Q^{*}$ for the $L \downarrow$ options: (a) 1, (b) 2, (c) 3 and (d) 4 for (top) LO02 and (bottom) BA03. The overall RMSE and MBE statistics, the linear regression (solid), and the 1:1 (dashed) lines are shown.

among the possible reasons for such a seasonal switch in the model biases.

For all options, the modeled daytime $Q_{H}$ overestimates the observed values for all seasons except MAM (Fig. 7j), where the maximum daytime magnitude of the flux is in good agreement with the measurements; whereas, $Q_{E}$ is underpredicted in all cases except MAM (Fig. 7n). This apparent trade-off between the two fluxes suggests that LUMPS would benefit from a more accurate partitioning of the available energy between the two turbulent processes. In particular, the correct characterization of the $\alpha$ and $\beta$ coefficients as a function of the site-specific surface characteristics is of critical importance (see Table 1). The analysis of nighttime $Q_{H}$ and $Q_{E}$ modeled values reveals a systematic bias from LUMPS, with a significant underestimation for all seasons but JJA; such a pattern, combined with the fact that the biggest bias is to be observed for the DJF period, hints at the importance of (nighttime) anthropogenic heating in Łódź (Klysik and Fortuniak 1999; Offerle et al. 2005, 2006), which is not in the base run. Finally, in the case of MAM (Figs. 7b, 7f, 7j, and 7n), LUMPS correctly simulates the daytime magnitude of the peak $Q^{*}, \Delta Q_{S}$, and $Q_{H}$ fluxes but overestimates the daytime $Q_{E}$; thus, not all of the available energy $\left(Q^{*}-\Delta Q_{S}\right)$ should be used (provided) by turbulent processes and some loss (gain) should occur via other sinks (sources) instead. The net advection of heat and moisture into/out of the area $\left(\Delta Q_{A}\right)$ can alter the turbulent exchanges, while $Q_{F}$ at night can complement $Q_{H}$ and $Q_{E}$ to provide the energy needed to close the balance (this is very likely the case in Figs. $7 \mathrm{i}$ and $7 \mathrm{~m}$ ). Rigorously, and following the notation from Offerle

TABLE 2. RMSE and MBE for modeling $Q^{*}$ using $L \downarrow$ options $1-4$ for all hourly data for Łódź and Baltimore (see text). Here, $N$ is the number of hours analyzed for each dataset.

\begin{tabular}{|c|c|c|c|c|c|c|c|c|c|c|c|c|c|}
\hline \multirow[b]{2}{*}{ Site } & \multirow[b]{2}{*}{$N$} & \multicolumn{4}{|c|}{$\operatorname{RMSE}\left(\mathrm{W} \mathrm{m}^{-2}\right)$} & \multicolumn{4}{|c|}{$\operatorname{MBE}\left(\mathrm{W} \mathrm{m}^{-2}\right)$} & \multicolumn{4}{|c|}{ Slope $(-) /$ intercept $\left(\mathrm{W} \mathrm{m}^{-2}\right)$} \\
\hline & & 1 & 2 & 3 & 4 & 1 & 2 & 3 & 4 & 1 & 2 & 3 & 4 \\
\hline LO01 & 3309 & 8.8 & 22.2 & 28.5 & 23.0 & 5.4 & 12.9 & 9.8 & -3.4 & $986 / 6.2$ & $1.002 / 12.8$ & $0.980 / 11.0$ & $0.971 /-1.7$ \\
\hline LO02 & 4582 & 8.7 & 22.7 & 26.3 & 21.6 & 6.2 & 14.8 & 11.5 & 0.4 & $0.994 / 6.6$ & $1.005 / 14.5$ & $0.982 / 12.6$ & $0.971 / 2.3$ \\
\hline BA01 & 1852 & 14.2 & 29.5 & 29.2 & 26.8 & 9.4 & 18.6 & 13.7 & -1.8 & $0.968 / 10.4$ & $0.976 / 19.4$ & $0.951 / 15.2$ & $0.955 /-0.4$ \\
\hline BA02 & 5285 & 16.9 & 29.5 & 28.4 & 28.0 & 7.2 & 16.9 & 5.7 & 2.7 & $0.947 / 11.0$ & $0.955 / 20.2$ & $0.938 / 10.3$ & $0.937 / 7.3$ \\
\hline BA03 & 4954 & 25.1 & 28.8 & 31.7 & 34.4 & 7.7 & 10.1 & 2.9 & -13.7 & $0.906 / 14.9$ & $0.920 / 16.3$ & $0.894 / 11.1$ & $0.930 /-8.4$ \\
\hline BA04 & 6508 & 22.1 & 27.4 & 28.0 & 29.4 & 12.2 & 13.2 & 5. & -9.7 & $0.939 / 17.8$ & $0.948 / 17.9$ & $0.937 / 11.5$ & $0.930 /-3.3$ \\
\hline BA05 & 5985 & 15.0 & 26.8 & 29.5 & 29.6 & 7.4 & 13.0 & 4.3 & -9.6 & $0.957 / 11.2$ & $0.954 / 17.0$ & $0.934 / 10.2$ & $0.930 /-3.5$ \\
\hline BA06 & 6719 & 16.9 & 26.6 & 29.0 & 28.7 & -3.5 & 16.1 & 8.1 & -8.3 & $0.950 / 1.6$ & $0.946 / 21.5$ & $0.931 / 15.1$ & $0.928 /-1.0$ \\
\hline
\end{tabular}



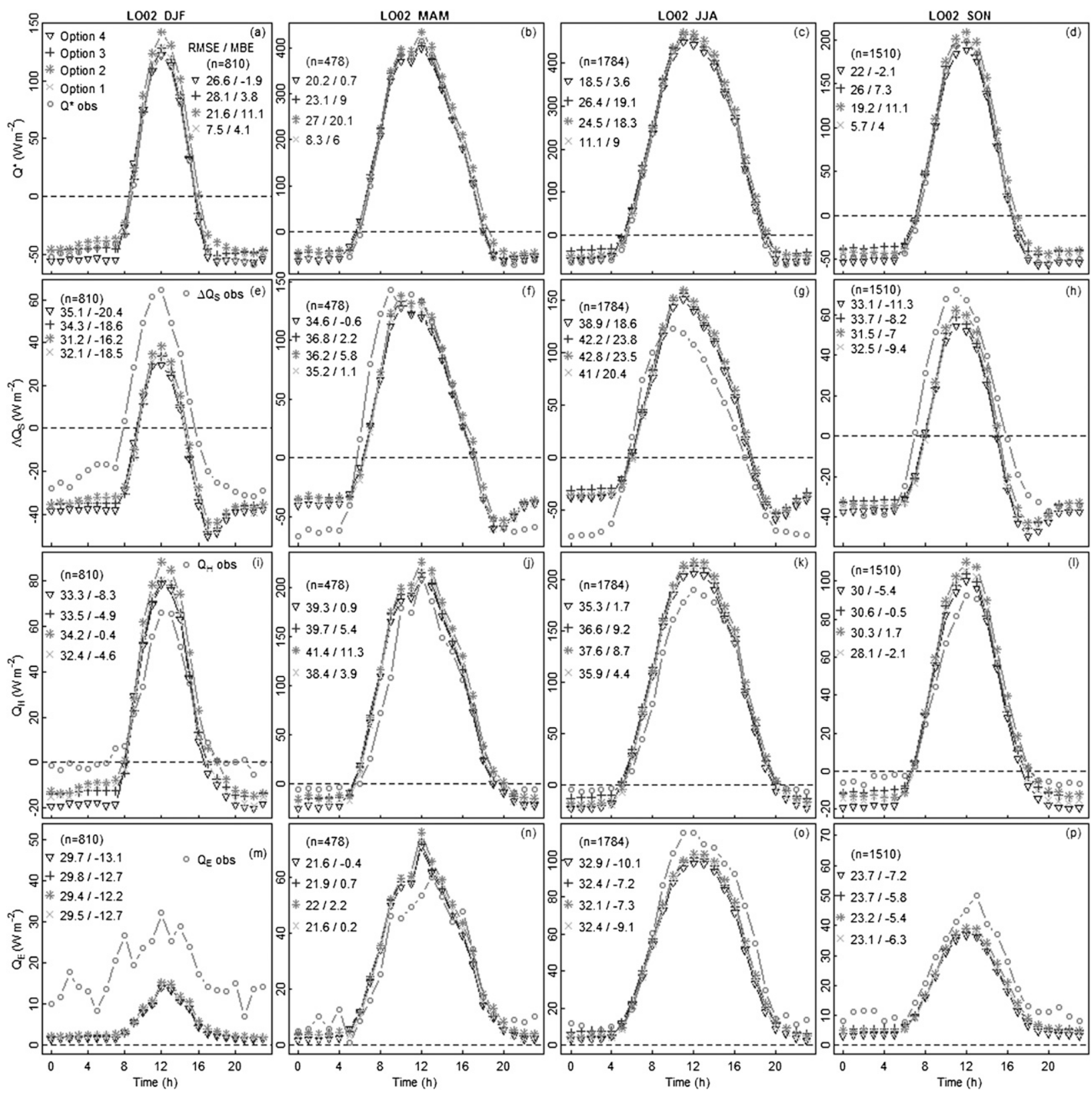

FIG. 7. Diurnal mean observed and modeled (a)-(d) $Q^{*}$, (e)-(h) $\Delta Q_{S}$, (i)-(l) $Q_{H}$, and (m)-(p) $Q_{E}$ fluxes for LO02 by season for (left) DJF, (left center) MAM, (right center) JJA, and (right) SON. See text for details on the modeling options. RMSE and MBE statistics are given.

et al. (2005), the energy available for turbulent processes should therefore be expressed as

$$
Q_{H}+Q_{E}=Q^{*}+Q_{F}-\Delta Q_{S}-\Delta Q_{A}-S
$$

where $S$ represents all sources and sinks of energy present at the scale of study, but not represented by the other terms, such as rainwater channeling heat out of the system or photosynthetic heat (Offerle et al. 2006). Such a detailed representation of these processes is however not the aim of a model like LUMPS, since it would require an increase in both the complexity of the parameterization involved and the amount of inputs required.

This study can also be seen as a sensitivity analysis of LUMPS to $L \downarrow$ and consequently to $Q^{*}$. Clearly, $L \downarrow$ is important in the surface energy balance and critical to $Q^{*}$, as well as being a key driver for $\Delta Q_{S}, Q_{H}$, and $Q_{E}$. However, the RMSE differences between the four $L \downarrow$ 
options $\left(<4 \mathrm{~W} \mathrm{~m}^{-2}\right)$ account for less than $10 \%$ of the overall RMSEs for $\Delta Q_{S}, Q_{H}$, and $Q_{E}$, which suggests that some other important processes are missing in LUMPS. These are needed to account for other types of energy transfers and limit the coupling between $Q^{*}$ and the rest of the fluxes.

\section{3) ANALysis OF MODEL ERROR}

To assess the importance of such unrepresented processes, an analysis of the model error dependency on a set of meteorological variables is performed. Plots of the error between the modeled (using $L \downarrow$ as forcing, i.e., option 1 as advised in section $3 \mathrm{a}$ ) and observed values of $Q^{*}, \Delta Q_{S}, Q_{H}$, and $Q_{E}$ for the 2-yr period as a function of air temperature, number of hours after a rain episode, wind direction, and wind speed (Fig. 8) provide insights into the importance of missing processes, including potential trends between the model error and variables. Assuming that $Q_{F}$ is closely correlated to the air temperature, the model error evolution as a function of $T_{a}$ should therefore reflect the importance of the $Q_{F}$ contribution to the SEB. Similarly, fetch characteristics are determined by wind direction while heat loss due to rainwater should decrease with time after a rain episode. LUMPS does not account for a decrease in the efficiency of the heat storage from urban surfaces at higher wind speeds, which should be reflected in the modeled SEB if turbulent transport is important.

The influence of rain episodes on the flux error is the least pronounced (Figs. 8e-h), although an underestimation of latent heat fluxes immediately after precipitation events (lowess curve and IQR for the first $12 \mathrm{~h}$ after rain below the 0 error line; see Fig. $8 \mathrm{~h}$ ) suggests that the surface may dry too rapidly and requires a lower dryness threshold, while the positive slope in the evolution of the error in $\Delta Q_{S}$ (Fig. 8f) indicates that the channeling of heat by rainwater might impact energy storage. Under weak winds, OHM underestimates the storage capacity (lowess and median for winds below $1 \mathrm{~m} \mathrm{~s}^{-1}$ below the 0 -error line) whereas it starts to overestimate it when wind speed values exceed $4 \mathrm{~m} \mathrm{~s}^{-1}$ (Fig. 8n). These results are in agreement with Meyn and Oke (2009), who suggest that the $a_{1}$ coefficient for built surfaces (Table 1) should decrease exponentially as a function of wind speed. The errors in the turbulent fluxes evolve in the opposite direction (i.e., toward an underestimation for strong winds). Caution should be used when interpreting the limited data for winds above $8 \mathrm{~m} \mathrm{~s}^{-1}$.

For all fluxes, the error is most sensitive to air temperature and wind direction (trends identified by the lowess curves and box-plot medians are more pronounced than for the other two variables). Figure 9, which separates daytime $(K \downarrow>0)$ and nighttime $(K \downarrow=0)$ errors, provides a more complete picture of the error dependency. Of particular interest is the underprediction of $Q_{H}$ for low nocturnal temperatures [between 20 and $50 \mathrm{~W} \mathrm{~m}^{-2}$ underprediction for $T_{a}<0^{\circ} \mathrm{C}$, as indicated by the solid lowess curve (Fig. $9 \mathrm{~g}$ ) or the median of the box plots], as it supports the hypothesis that anthropogenic heating plays an important role, particularly in the nocturnal energy balance. Without an explicit representation of $Q_{F}$, LUMPS assumes that all of the $\left(Q^{*}-\Delta Q_{S}\right)$ nighttime energy deficit is to be compensated by turbulent heat exchange and consequently simulates large negative $Q_{H}$ (and $Q_{E}$ ) fluxes when these should be close to zero (see Fig. 7i) with the additional input of heat from $Q_{F}$. This clear underprediction of LUMPS is reduced when temperatures increase $\left(\sim 10 \mathrm{~W} \mathrm{~m}^{-2}\right.$ underprediction), with a threshold around $7{ }^{\circ} \mathrm{C}$ (vertical line in Figs. 9a-h). During the day, the trend is less pronounced, but still noticeable and leads to the overprediction of $Q_{H}$ for positive temperatures, hence confirming the day time maximum overestimations identified from Fig. 7. The evolution of the error in the modeled $\Delta Q_{S}$ and $Q^{*}$ (Figs. 9a, 9b, 9e, and 9f) also exhibits a marked change in slope around this same threshold temperature of $7^{\circ} \mathrm{C}$. For high temperatures, and especially at night, LUMPS overestimates $Q^{*}$ (by up to $10 \mathrm{~W} \mathrm{~m}^{-2}$; Figs. 9a and $9 \mathrm{e}$ ) and $\Delta Q_{S}$ (by up to $40 \mathrm{~W} \mathrm{~m}^{-2}$; Figs. $9 \mathrm{~b}$ and $9 \mathrm{f}$ ). The biggest errors in modeling $\Delta Q_{S}$ are found at temperatures above $20^{\circ} \mathrm{C}$, confirming some limitations of OHM in the summer (Fig. $7 \mathrm{~g}$ ).

The analysis of error dependency by wind direction is only possible with respect to the tower location. The surface cover fractions around the site (see Fig. 2 in Offerle et al. 2006) have a clear contrast between the more vegetated section west of the tower [wind direction from $150^{\circ}$ to $330^{\circ}$; Offerle et al. (2006)] and the rest of the area (more urbanized). The lowess trend for $Q_{H}$ clearly depicts a strong influence of the fetch characteristics on the magnitude and sign of the error [up to $30 \mathrm{~W} \mathrm{~m}^{-2}$ overestimation from the lowess when the wind is from the south during the daytime, with a median of $\sim 50 \mathrm{~W} \mathrm{~m}^{-2}$ for wind directions in the range $220^{\circ}$ $240^{\circ}$ (Fig. 9k) and down to a $30 \mathrm{~W} \mathrm{~m}^{-2}$ underestimation from the lowess when the wind is from the north at night (Fig. 9o)]. For $Q_{E}$, the lowess follows the 0 -error line and the spread of points is considerably smaller (see IQR; Figs. 91 and 9p) and less impacted by wind direction. A tendency toward underestimation when the wind comes from the north is noted, with the lowess going below the 0 -error line and the IQR increasing. In the base run, fixed surface characteristics were used, so some of the errors can be attributed to the variability in the observed values. During the day, LUMPS overpredicts if the 

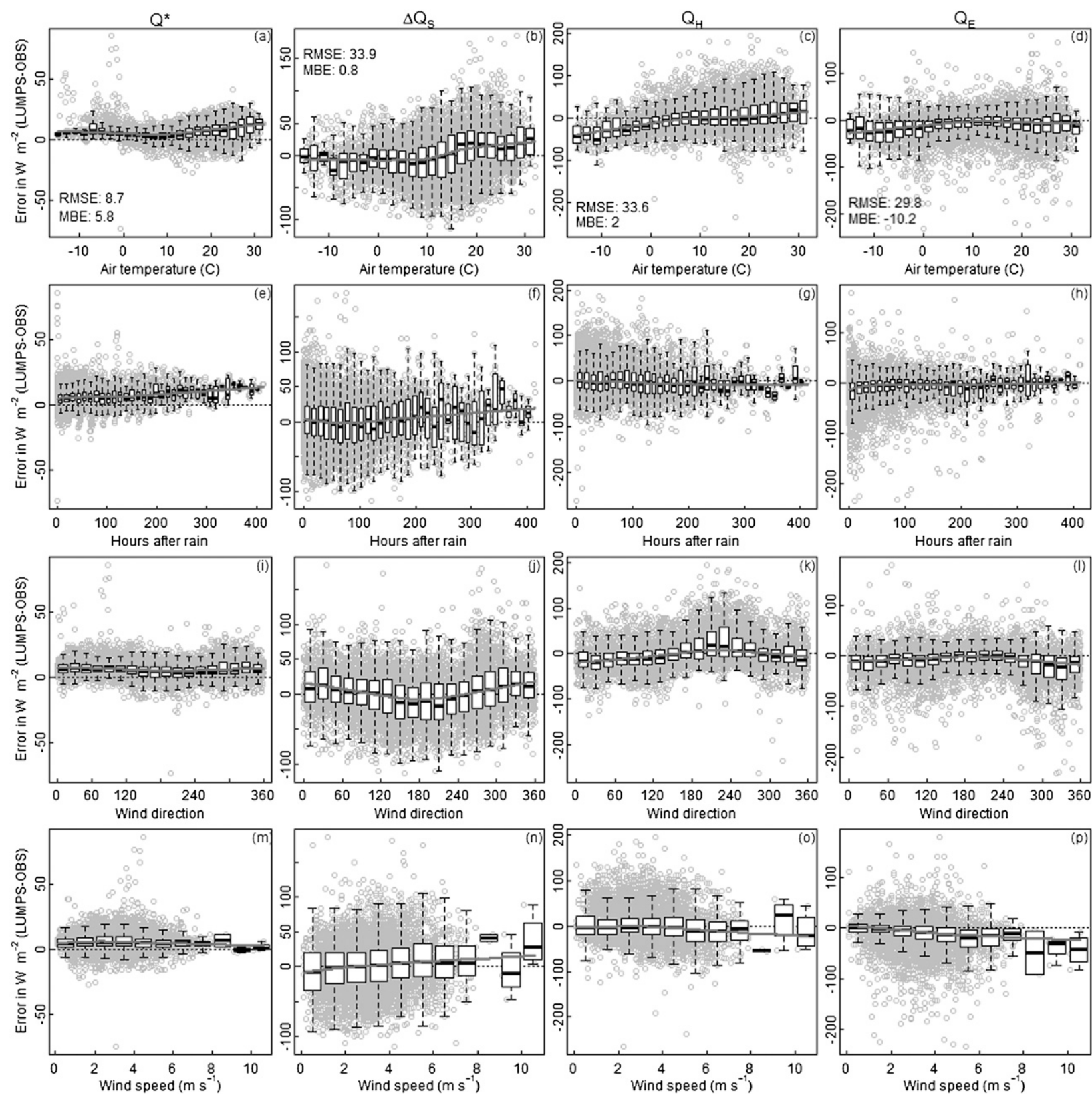

FIG. 8. Error between modeled (using $L \downarrow$ option 1) and observed values of $Q^{*}, \Delta Q_{S}, Q_{H}$, and $Q_{E}$ for the entire 2-yr period as a function of (a)-(d) air temperature, (e)-(h) number of hours after a rain episode, (i)-(l) wind direction, and (m)-(p) wind speed. Zero-error (horizontal, dashed) and lowess (solid) lines are shown. Box plots are for bins of $2^{\circ} \mathrm{C}$ temperature for (a)-(d), $12 \mathrm{~h}$ after rain for (e)-(h), $20^{\circ}$ wind direction for (i)-(1), and $1 \mathrm{~m} \mathrm{~s}^{-1}$ wind speed for (m)-(p). RMSE and MBE statistics over the 2 yr are indicated in (a)-(d).

footprint extends to more vegetated surfaces; for $Q_{E}$, the tendency is toward an underprediction when the fluxes are from the urbanized sector, which disappears when they are from the vegetated one. As observed from Fig. 7, the nighttime turbulent activity modeled by LUMPS appears to be systematically larger than suggested by the measurements (larger negative $Q_{H}$ values). When the fetch is from the more urbanized sector, the observed $Q_{H}$ fluxes are likely to be small (near-neutral condition), therefore leading to negative errors (see Fig. 9o for wind directions between $0^{\circ}$ and $120^{\circ}$ ), while for a more vegetated source area (e.g., southsouthwest of the tower) the nighttime negative fluxes are closer to the actual observed values and the error becomes smaller. These conclusions extend to the evolution of the error in the estimation of $\Delta Q_{S}$ (Figs. 9j and 9n) given the 

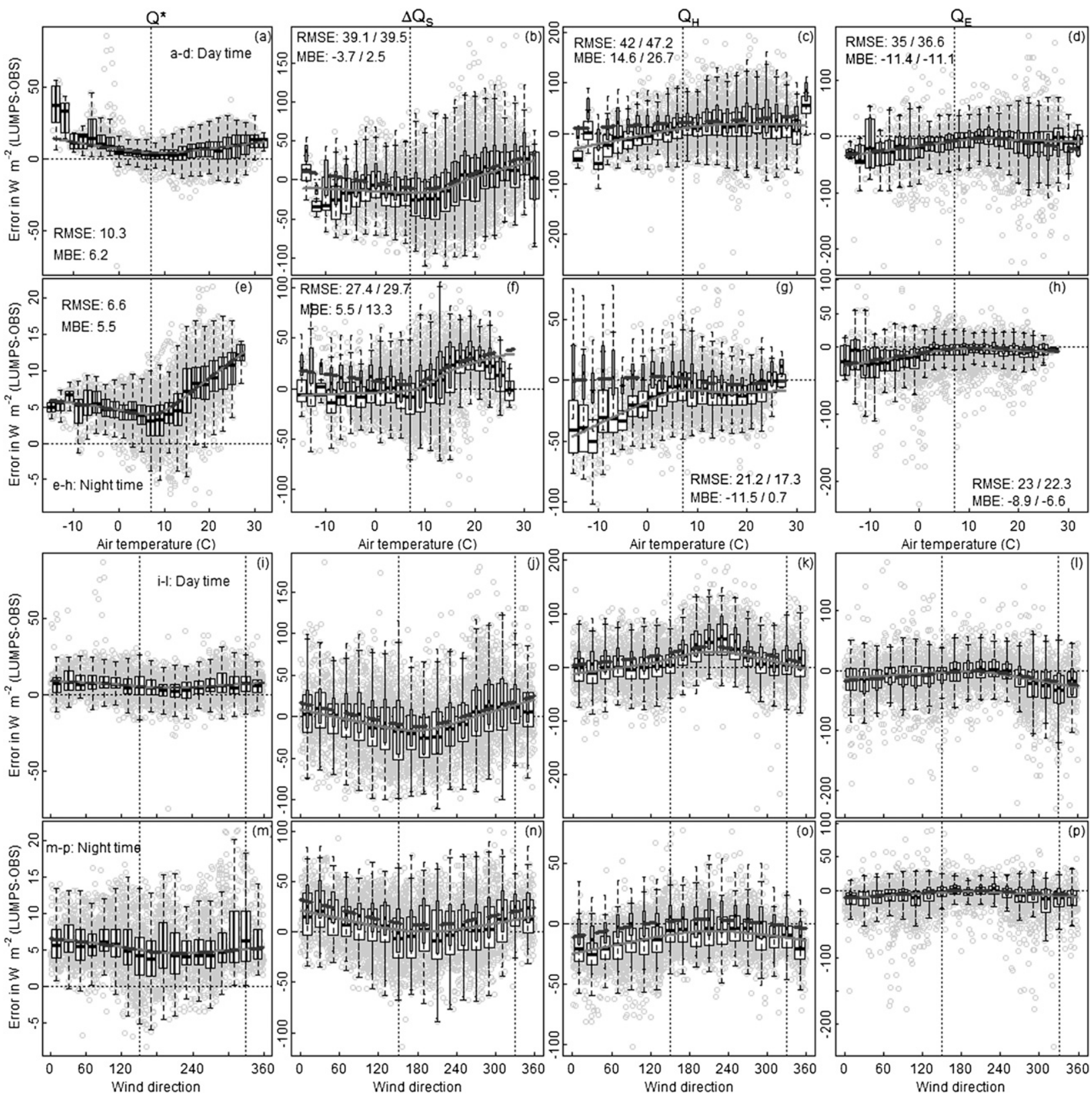

FIG. 9. Error [(a)-(d),(i)-(l) daytime and (e)-(h),(m)-(p) nighttime] between modeled (using $L \downarrow$ option 1 ) and observed values of $Q^{*}, \Delta Q_{S}$, $Q_{H}$, and $Q_{E}$ for the 2-yr period as a function of (top and top middle) air temperature and (bottom and bottom middle) wind direction. Lowess lines for base run (solid) and run $2\left(Q_{F}\right.$, changing surface characteristics) (dashed). Box plots (white—wider for the base run; gray-narrower run 2 are for bins of $2^{\circ} \mathrm{C}$ temperature for (a)-(h) and $20^{\circ}$ wind direction for (i)-(p). RMSE and MBE statistics are indicated in (a) -(h) for base run (left) and run 2 (right). For $Q^{*}$, both runs are the same. See text for definition of the vertical threshold (dashed) lines.

direct link between $\Delta Q_{S}$ and the turbulent fluxes in LUMPS. During the day, the overestimation of $Q_{H}$ (Fig. 9k) is matched by an underestimation of $\Delta Q_{S}$ (Fig. 9j) and vice versa. At night, $\Delta Q_{S}$ is overestimated when the wind comes from the more urbanized sector and the lowess trend is close to the 0 -error line when it is from the south, which is an inverse correlation with the trend in the error for $Q_{H}$.
Note that $Q^{*}$ is not particularly sensitive to wind direction (as shown by the lowess curve position and the small IQR; Figs. 9i and $9 \mathrm{~m}$ ) but the lowess and medians show a constant LUMPS overprediction of around $5 \mathrm{~W} \mathrm{~m}^{-2}$.

These results suggest that an important process currently missing in LUMPS is the representation of $Q_{F}$. It also suggests that for model evaluation purposes the 
characterization of the flux footprint is important for assigning parameter values.

\section{4) ANTHRopogenic HEAT AND DYNAMIC SURFACE FOOTPRINT}

The approach taken to include $Q_{F}$ is described in Eq. (13). The parameter values were assigned for Łódź (Table 1 ) as $Q_{F, \text { min }}=15 \mathrm{~W} \mathrm{~m}^{-2}$ [see typical July values reported in Klysik (1996) for the city of Łódź] and the slope $Q_{F \text {,slope }}$ matches the $2.7 \mathrm{~W} \mathrm{~m}^{-2}{ }^{\circ} \mathrm{C}^{-1}$ identified by Offerle et al. (2005) during October-March 2001-02. The value of the critical temperature $\left(T_{c}\right)$ is assumed to be $7^{\circ} \mathrm{C}$ from the error evolution plots (Figs. $9 \mathrm{c}$ and $9 \mathrm{~g}$ ).

Following Grimmond and Oke (1991, 2002), a dynamic flux footprint for the hourly surface characteristics is computed by Offerle et al. (2006) using Schmid's (1994) Flux Source Area Model (FSAM) with a $5 \mathrm{~km} \times$ $5 \mathrm{~km}$ GIS grid (spatial resolution $=100 \mathrm{~m}$ ) centered on the measurement tower. The database of buildings $\left(f_{\text {build }}\right)$, vegetated $\left(f_{\text {veg }}\right)$, and impervious $\left(f_{\text {imp }}\right)$ surface covers allows us to calculate the $a_{1 \mathrm{i}}, a_{2 \mathrm{i}}$, and $a_{3 \mathrm{i}}$ coefficients for $\Delta Q_{S}$, as well as $\alpha$ and $\beta$ in the turbulent heat fluxes, at each time step (see Table 1). This offers a better characterization of the fetch variability and allows for better accountability of daily-seasonal changes in the stability and wind patterns in the observations.

The performance from run 2 of LUMPS is indicated by a second set of lowess (dashed) curves and (gray narrower) box plots in Fig. 9. RMSE and MBE statistics for the two simulations are presented in Figs. 9a-h (base run/ run 2). The impacts of the additional $Q_{F}$ are clearly noticeable in Fig. 9g, where the nighttime negative bias in $Q_{H}$ for low temperatures is removed (the dashed lowess curve and medians follow the zero-error line) and the corresponding $\mathrm{MBE}$ is reduced by $>10 \mathrm{~W} \mathrm{~m}^{-2}$; that is, the $\left(Q^{*}-\Delta Q_{S}\right)$ energy deficit is compensated by $Q_{F}$ input rather than a negative $Q_{H}$. The impacts on nighttime $Q_{E}$ are limited (Fig. 9h) but the MBE was reduced by $2.3 \mathrm{~W} \mathrm{~m}^{-2} ; \Delta Q_{S}$ is overestimated at low temperatures (Fig. 9f) and now is more obviously related to the overpredicted $Q^{*}$ (Fig. 9e). Given the larger magnitude of the fluxes during the day, the impacts of $Q_{F}$ are less obvious (Figs. 9b-d). A systematic overestimation of $Q_{H}$ values regardless of temperature occurs and suggests that the daytime performance has declined with $Q_{F}$ inclusion. This is confirmed by the statistics $\left(\sim 12 \mathrm{~W} \mathrm{~m}^{-2}\right.$ increase in daytime MBE). The pattern in $\Delta Q_{S}$ error leads to better agreement with $Q^{*}$ than was previously found (i.e., an overestimation of $Q^{*}$ should trigger an overestimation of $\Delta Q_{S}$ ). As the $Q^{*}$ results are not impacted by the two modifications, the statistics are identical.

The errors with wind direction (Figs. 9i-p), when the dynamical footprint surface fractions are used, produce small differences. When the wind originates from the vegetated sector, the lowess curves and medians of the $Q_{E}$ error (Figs. 91 and 9p) are now slightly closer to zero. Similarly, the difference in daytime $\Delta Q_{S}$ between the two runs (Fig. 9j) is more pronounced when the footprint is from the more urbanized sector $\left(0^{\circ}-150^{\circ}\right)$, indicating $\Delta Q_{S}$ from the vegetated sector has been reduced. The systematic overestimation of the daytime $Q_{H}$ values is clearly noticeable (Fig. 9c), while nighttime performance shows some significant improvement (Fig. 9o).

The benchmarking procedure of E. Blyth and M. Pryor (2010, personal communication) was applied to check for statistically significant changes in the mean modeled $Q_{H}$, $Q_{E}$, and $\Delta Q_{S}$ values between the base run and run 2 using a two-sided $t$ test with a Welsh correction to assume non equal variance (Adler 2010). Results indicate that significant improvements in the model performance are found for $Q_{H}$ and $Q_{E}$ during the nighttime as well as $\Delta Q_{S}$ during the day. The modeling of $Q_{E}$ for run 2 does not provide any significant difference from the base run during the daytime, while daytime $Q_{H}$ and nighttime $\Delta Q_{S}$ significantly degrades for run 2.

Thus, we conclude that the addition of $Q_{F}$, in its current form, helps remove the systematic biases in nighttime turbulent fluxes of $Q_{H}$, but generates a daytime systematic overestimation. The evolution of $\Delta Q_{S}$ also results in more coherence with $Q^{*}$ biases when $Q_{F}$ is included. Any improvement in modeling $Q^{*}$ should be reflected in $\Delta Q_{S}$, when the modeled energy balance accounts for a $Q_{F}$ contribution. The use of variable measurement footprint characteristics did not provide as much improvement as expected but did result in slightly better performance from the more vegetated sector (lower $\Delta Q_{S}$ and $Q_{H}$, and higher $\left.Q_{E}\right)$. The limited overall improvement from these simple modifications demonstrates the difficulty in representing such processes with a restricted level of complexity. It also highlights the strength of the flux formulations in LUMPS' ability to simulate the overall magnitude of the surface energy balance in urban areas (overall RMSE $<34 \mathrm{~W} \mathrm{~m}^{-2}$ for all fluxes over the 2 yr of data from Łódź; Fig. 8) from an extremely limited amount of input information. Further efforts to better represent surface variability and anthropogenic heat without any radical change in the level of modeling complexity involved are however still needed.

\section{Conclusions}

The simple model LUMPS now incorporates the NARP radiation model, changing availability of water at the surface, vegetation phenology, and a simple anthropogenic heat flux model. These new developments have been accomplished while maintaining the need for limited forcing data and surface information. 
Several alternatives to modeling incoming longwave radiation from commonly available data are considered. A simple formulation based on relative humidity, air temperature, and vapor pressure is developed with cloud fraction data from a site in central London before being tested at two independent sites (Łódź, Poland, and Baltimore, Maryland). The performance of this simple parameterization is compared with the method of Offerle et al. (2003), based on observed incoming solar radiation and an estimate of its clear-sky value. A third alternative uses observed cloud data from the National Climatic Data Center. Although the performances of the two approaches in modeling the cloud fraction are very similar, it can be argued that the new formulation exhibits less bias at night and has the advantage of a wider applicability. In all cases the use of the observed cloud fraction information leads to an increased level of performance in the modeling of $L \downarrow$.

In the second part of the study, the impacts of the $L \downarrow$ approach are evaluated as part of an assessment of LUMPS's ability to simulate the surface energy balance fluxes. Results highlight the good overall performance of the scheme [overall RMSE $<34 \mathrm{~W} \mathrm{~m}^{-2}$ for all fluxes over the $2 \mathrm{yr}$ of data from Łódź when using $L \downarrow$ as the forcing (Fig. 8) and RMSE $<43 \mathrm{~W} \mathrm{~m}^{-2}$ for all seasons and all $L \downarrow$ options in 2002 (Fig. 7)]. Analysis of the error evolution as a function of air temperature and wind direction suggests that an explicit representation of anthropogenic heat and a better characterization of the flux footprint in LUMPS are useful.

Acknowledgments. Thanks are given to all those who were involved in the Baltimore, Łódź, and London field campaigns, especially John Hom (USDA FS), Krzysztof Fortuniak (UL), Alastair Reynolds (KCL), and Steve Scott (IU). Thanks are also given to Eleanor Blyth (CEH) and Matt Pryor (Met Office) for discussions about JULES benchmarking. Financial support for this project for the fieldwork and the analyses was provided to SG by the U.S. National Science Foundation (ATM-0710631, BCS0221105, BCS-0095284), EU (FP7-ENV-2007-1 211345) BRIDGE, Met Office, USDA Forest Service (CA11242343-082, 04-CA-11242343-124, 05-CA-11242343-11), and King's College London. The LUMPS model is available online (http:/geography.kcl.ac.uk/micromet/index.htm).

\section{REFERENCES}

Adler, J., 2010: $R$ in a Nutshell. O'Reilly Media, 611 pp.

Allen, L., F. Lindberg, and C. S. B. Grimmond, 2010: Global to city scale urban anthropogenic heat flux: Model and variability. Int. J. Climatol., in press, doi:10.1002/joc.2210.

Baklanov, A., J. Ching, C. S. B. Grimmond, and A. Martilli, 2009: Model urbanization strategies: Summaries, recommendations and requirements. Urbanization of Meteorological and Air Quality Models, A. Baklanov et al., Eds., Springer-Verlag, 151-162.

Bradley, E., T. Hastie, I. Johnstone, and R. Tibshirani, 2004: Least angle regression. Ann. Stat., 32, 407-499, doi:10.1214/ 009053604000000067.

Cimorelli, A. J., and Coauthors, 2005: AERMOD: A dispersion model for industrial source applications. Part I: General model formulation and boundary layer characterization. J. Appl. Meteor., 44, 682-693.

Cleveland, W. S., 1981: LOWESS: A program for smoothing scatterplots by robust locally weighted regression. Amer. Stat., 35,54 .

Crawford, T. M., and C. E. Duchon, 1999: An improved parameterization for estimating effective atmospheric emissivity for use in calculating daytime downwelling longwave radiation. J. Appl. Meteor., 38, 474-480.

de Bruin, H. A. R., and A. A. M. Holtslag, 1982: A simple parameterization of surface fluxes of sensible and latent heat during daytime compared with the Penman-Monteith concept. J. Appl. Meteor., 21, 1610-1621.

Emeis, S., C. Munkel, S. Vogt, W. J. Muller, and K. Schäfer, 2004: Atmospheric boundary-layer structure from simultaneous SODAR, RASS, and ceilometers measurements. Atmos. Environ., 34, 273-286.

Eresmaa, N., A. Karppinen, S. M. Joffre, J. Rasanen, and H. Talvitie, 2006: Mixing height determination by ceilometer. Atmos. Chem. Phys., 6, 1485-1493.

Flanner, M. G., 2009: Integrating anthropogenic heat flux with global climate models. Geophys. Res. Lett., 36, L02801, doi:10.1029/ 2008GL036465.

Grimmond, C. S. B., and T. R. Oke, 1991: An evaporationinterception model for urban areas. Water Resour. Res., 27, 1739-1755.

_, and - 1999: Heat storage in urban areas: Observations and evaluation of a simple model. J. Appl. Meteor., 38, 922-940.

_, and — 2002: Turbulent heat fluxes in urban areas: Observations and a Local-Scale Urban Meteorological Parameterization Scheme (LUMPS). J. Appl. Meteor., 41, 792-810.

- H. A. Cleugh, and T. R. Oke, 1991: An objective urban heat storage model and its comparison with other schemes. Atmos. Environ., 25B, 311-326.

— B. D. Offerle, J. Hom, and D. Golub, 2002: Observation of local-scale heat, water, momentum and $\mathrm{CO} 2$ fluxes at $\mathrm{Cub}$ Hill, Baltimore. Preprints, Fourth Urban Environment Symp., Norfolk, VA, Amer. Meteor. Soc., 10.6. [Available online at http://ams.confex.com/ams/pdfpapers/37022.pdf.]

— ternational Urban Energy Balance Comparison. Int. J. Climatol., in press, doi:10.1002/joc.2227.

— , and Coauthors, 2010b: The International Urban Energy Balance Models Comparison Project: First results from phase 1. J. Appl. Meteor. Climatol., 49, 1268-1292.

Holtslag, A. A. M., and A. P. van Ulden, 1983: A simple scheme for daytime estimates of the surface fluxes from routine weather data. J. Climate Appl. Meteor., 22, 517-529.

Kastner-Klein, P., and M. W. Rotach, 2004: Mean flow and turbulence characteristics in an urban roughness sublayer. Bound.-Layer Meteor., 111, 55-84.

Kikegawa, Y., Y. Genshi, H. Yoshikado, and H. Kondo, 2003: Development of a numerical simulation system toward comprehensive assessments of urban warming countermeasures 
including their impacts upon the urban buildings' energy demands. Appl. Energy, 76, 449-466.

Klysik, K., 1996: Spatial and seasonal distribution of anthropogenic heat emissions in Łódź, Poland. Atmos. Environ., 30, 3397-3404. , and K. Fortuniak, 1999: Temporal and spatial characteristics of the urban heat island of Łódź, Poland. Atmos. Environ., 33, 3885-3895.

Lindberg, F., B. Holmer, and S. Thorsson, 2008: SOLWEIG 1.0-Modelling spatial variations of 3D radiant fluxes and mean radiant temperature in complex urban settings. Int. J. Biometeor., 52, 697-713.

Loridan, T., and Coauthors, 2010: Trade-offs and responsiveness of the single-layer urban canopy parameterization in WRF: An offline evaluation using the MOSCEM optimization algorithm and field observations. Quart. J. Roy. Meteor. Soc., 136, 9971019, doi:10.1002/qj.614.

Masson, V., 2006: Urban surface modelling and the meso-scale impact of cities. Theor. Appl. Climatol., 84, 35-45.

McCaughey, H., 1985: Energy balance storage terms in a mature mixed forest at Petawawa Ontario-A case study. Bound.Layer Meteor., 31, 89-101.

Meyn, S. K., and T. R. Oke, 2009: Heat fuxes through roofs and their relevance to estimates of urban heat storage. Energy Build., 41, 745-752.

NCDC, cited 2009: National Climatic Data Center. [Available online at http://www.ncdc.noaa.gov/oa/ncdc.html.]

Offerle, B., 2003: The energy balance of an urban area: Examining temporal and spatial variability through measurements, remote sensing and modelling. Ph.D. thesis, Indiana University, $218 \mathrm{pp}$.

, C. S. B. Grimmond, and T. R. Oke, 2003: Parameterization of net all-wave radiation for urban areas. J. Appl. Meteor., 42, $1157-1173$.
,-- , and K. Fortuniak, 2005: Heat storage and anthropogenic heat flux in relation to the energy balance of a central European city center. Int. J. Climatol., 25, 1405-1419, doi:10.1002/ joc.1198.

,,,--- K. Klysik, and T. R. Oke, 2006: Temporal variations in heat fluxes over a central European city centre. Theor. Appl. Climatol., 84, 103-116.

Oke, T. R., 1987: Boundary Layer Climates. Routledge, 435 pp.

Perry, S. G., 1992: CTDMPLUS: A dispersion model for sources in complex topography. Part I: Technical formulations. J. Appl. Meteor., 31, 633-645.

Pigeon, G., D. Legain, P. Durand, and V. Masson, 2007: Anthropogenic heat releases in an old European agglomeration (Toulouse, France). Int. J. Climatol., 27, 1969-1981.

Prata, A. J., 1996: A new long-wave formula for estimating downward clear-sky radiation at the surface. Quart. J. Roy. Meteor. Soc., 122, 1127-1151.

Sailor, D. J., and L. Lu, 2004: A top-down methodology for developing diurnal and seasonal anthropogenic heating profiles for urban areas. Atmos. Environ., 38, 2737-2748.

Schmid, H. P., 1994: Source areas for scalars and scalar fluxes. Bound.-Layer Meteor., 67, 293-318.

Smith, W. L., 1966: Note on the relationship between total precipitable water and surface dewpoint. J. Appl. Meteor., 5, 726-727.

Taha, H., 1999: Modifying a mesoscale meteorological model to better incorporate urban heat storage: A bulk-parameterization approach. J. Appl. Meteor., 38, 466-473.

Vaisala Oyj, 2006: Vaisala Ceilometer CL31 user's guide. Vaisala Oyj, Helsinki, Finland, 134 pp.

van Ulden, A. P., and A. A. M. Holtslag, 1985: Estimation of atmospheric boundary layer parameters for diffusion applications. J. Climate Appl. Meteor., 24, 1196-1207. 